University of Nebraska - Lincoln

DigitalCommons@University of Nebraska - Lincoln

\title{
Dissolution of uranyl microprecipitates in subsurface sediments at Hanford Site, USA
}

Chongxuan Liu

Pacific Northwest National Laboratory, chongxuan.liu@pnl.gov

John M. Zachara

Pacific Northwest National Laboratory, john.zachara@pnl.gov

Odeta Qafoku

Pacific Northwest National Laboratory

James Mckinley

Pacific Northwest National Laboratory, james.mckinley@pnl.gov

Steve M. Heald

Pacific Northwest National Laboratory, steve.heald@pnl.gov

See next page for additional authors

Follow this and additional works at: https://digitalcommons.unl.edu/usdoepub

Part of the Bioresource and Agricultural Engineering Commons

Liu, Chongxuan; Zachara, John M.; Qafoku, Odeta; Mckinley, James; Heald, Steve M.; and Wang, Zheming, "Dissolution of uranyl microprecipitates in subsurface sediments at Hanford Site, USA" (2004). US Department of Energy Publications. 256.

https://digitalcommons.unl.edu/usdoepub/256

This Article is brought to you for free and open access by the U.S. Department of Energy at DigitalCommons@University of Nebraska - Lincoln. It has been accepted for inclusion in US Department of Energy Publications by an authorized administrator of DigitalCommons@University of Nebraska - Lincoln. 


\section{Authors}

Chongxuan Liu, John M. Zachara, Odeta Qafoku, James Mckinley, Steve M. Heald, and Zheming Wang 
doi:10.1016/j.gca.2004.04.017

\title{
Dissolution of uranyl microprecipitates in subsurface sediments at Hanford Site, USA
}

\author{
Chongxuan Liu, ${ }^{1, *}$ John M. Zachara, ${ }^{1}$ Odeta Qafoku, ${ }^{1}$ James P. McKinley, ${ }^{1}$ Steve M. Heald, ${ }^{1,2}$ and Zheming Wang ${ }^{1}$ \\ ${ }^{1}$ Pacific Northwest National Laboratory, P.O. Box 999, MSIN K8-96, Richland, WA 99352, USA \\ ${ }^{2}$ PNC-CAT Argonne National Laboratory, 9700 S. Cass Ave., Argonne, IL 60439, USA
}

(Received December 8, 2003; accepted in revised form April 26, 2004)

\begin{abstract}
The dissolution of uranium was investigated from contaminated sediments obtained at the US. Department of Energy (U.S. DOE) Hanford site. The uranium existed in the sediments as uranyl silicate microprecipitates in fractures, cleavages, and cavities within sediment grains. Uranium dissolution was studied in $\mathrm{Na}, \mathrm{Na}-\mathrm{Ca}$, and $\mathrm{NH}_{4}$ electrolytes with $\mathrm{pH}$ ranging from 7.0 to 9.5 under ambient $\mathrm{CO}_{2}$ pressure. The rate and extent of uranium dissolution was influenced by uranyl mineral solubility, carbonate concentration, and mass transfer rate from intraparticle regions. Dissolved uranium concentration reached constant values within a month in electrolytes below $\mathrm{pH} 8.2$, whereas concentrations continued to rise for over $200 \mathrm{~d}$ at $\mathrm{pH} 9.0$ and above. The steady-state concentrations were consistent with the solubility of Na-boltwoodite and/or uranophane, which exhibit similar solubility under the experimental conditions. The uranium dissolution rate increased with increasing carbonate concentration, and was initially fast. It decreased with time as solubility equilibrium was attained, or dissolution kinetics or mass transfer rate from intraparticle regions became rate-limiting. Microscopic observations indicated that uranium precipitates were distributed in intragrain microfractures with variable sizes and connectivity to particle surfaces. Laser-induced fluorescence spectroscopic change of the uranyl microprecipitates was negligible during the long-term equilibration, indicating that uranyl speciation was not changed by dissolution. A kinetic model that incorporated mineral dissolution kinetics and grain-scale, fracture-matrix diffusion was developed to describe uranium release rate from the sediment. Model calculations indicated that $50-95 \%$ of the precipitated uranium was associated with fractures that were in close contact with the aqueous phase. The remainder of the uranium was deeply imbedded in particle interiors and exhibited effective diffusivities that were over three orders of magnitude lower than those in the fractures. Copyright (C) 2004 Elsevier Ltd
\end{abstract}

\section{INTRODUCTION}

Uranium $(\mathrm{U})$ is a common subsurface contaminant at United States Department of Energy (DOE) sites resulting from its central role in the nuclear fuel cycle (Riley and Zachara, 1992). The geochemical behavior of $U$, including its reactive transport chemistry and potential for remediation, is a matter of concern and intensive research. Subsurface uranium mobility is controlled by adsorption to mineral materials and dissolution/ precipitation of uranium solids. Uranium is hexavalent [U(VI)] under oxidized conditions and exists as the uranyl ion $\left(\mathrm{UO}_{2}{ }^{2+}\right)$ and its complexes with various ligands in aqueous phase (Langmuir, 1978; Grenthe et al., 1992).

$\mathrm{U}(\mathrm{VI})$ is sorbed to fixed charge sites on phyllosilicates by ion exchange (McKinley et al., 1995; Turner et al., 1996), and to hydroxylated mineral surfaces including the edges of phyllosilicates and $\mathrm{Al}(\mathrm{III}), \mathrm{Fe}(\mathrm{III})$, and $\mathrm{Si}(\mathrm{IV})$ oxides by complexation (Hsi and Langmuir, 1985; Waite et al., 1994; McKinley et al., 1995; Duff and Amrhein, 1996; Hudson et al., 1999; Payne et al., 1996; Turner et al., 1996; Bargar et al., 1999, 2000; Lenhart and Honeyman, 1999; Sylwester et al., 2000; Davis et al., 2002). The U(VI) adsorption process is often described using equilibrium surface complexation models (e.g., McKinley et al., 1995; Waite et al., 2000; Davis et al., 2002).

Studies of U(VI) desorption are limited. The desorption rate of $\mathrm{U}$ from laboratory-spiked pristine materials (Fuhrmann et al., 1997; Ohnuki et al., 1997; Giammar and Hering,

* Author to whom correspondence should be addressed, at (Chongxuan.liu@pnl.gov).
2001) and U-contaminated sediments (Braithwaite et al., 1997; Mason et al., 1997) was found to decrease with increasing exposure time to uranium contamination. For example, desorption equilibrium of U(VI) from goethite after aging for 1 month was achieved rapidly, but much slower desorption was observed after aging for 6 months (Giammar and Hering, 2001). Braithwaite et al. (1997) observed that the desorption half-life for sediments that were exposed to the long term U(VI) contamination was more than $10 \mathrm{yr}$. Slow desorption kinetics are generally attributed to diffusion from and/or occlusion of U(VI) within intraparticle regions, or reduction to $\mathrm{U}(\mathrm{IV})$. Little is known about the influences of speciation, sorptive location and mineral phases, and diffusion on U(VI) release from contaminated sediments.

Investigations of the rates of uranyl mineral dissolution and of the factors influencing the rates are also limited. One laboratory study indicated that U(VI) mineral dissolution was influenced by the nature of complexing ligands and their strength of binding U(VI) (Sowder et al., 2001). The dissolution rates of metashoepite $\left[\left(\mathrm{UO}_{2}\right)_{8} \mathrm{O}_{2}(\mathrm{OH})_{12}\left(\mathrm{H}_{2} \mathrm{O}\right)_{10}\right]$ and becquerelite $\left[\mathrm{Ca}\left(\mathrm{UO}_{2}\right)_{6} \mathrm{O}_{4}(\mathrm{OH})_{6}\left(\mathrm{H}_{2} \mathrm{O}\right)_{8}\right]$ were faster than those for metaautunites $\left[\mathrm{Ca}\left(\mathrm{UO}_{2}\right)_{2}\left(\mathrm{PO}_{4}\right)_{2}\left(\mathrm{H}_{2} \mathrm{O}\right)_{\mathrm{x}}\right]$ and chernikovite $\left[\mathrm{UO}_{2} \mathrm{HPO}_{4}\left(\mathrm{H}_{2} \mathrm{O}\right)_{4}\right]$ in solutions of acetic acid and EDTA, while becquerelite and chernikovite were slower than metashoepite and metaautunite in bicarbonate solutions. Higher concentrations of complexants, including bicarbonate, caused more rapid dissolution. The rate and extent of dissolution of U(VI)-oxides (Steward and Mones, 
1997), uranophane $\left[\mathrm{Ca}\left(\mathrm{UO}_{2}\right)_{2}\left(\mathrm{SiO}_{3} \mathrm{OH}\right)_{2}\left(\mathrm{H}_{2} \mathrm{O}\right)_{5}\right]$ (Perez et al., 2000), and soddyite $\left[\left(\mathrm{UO}_{2}\right)_{2} \mathrm{SiO}_{4}\left(\mathrm{H}_{2} \mathrm{O}\right)_{2}\right]$ (Perez et al., 1997) all increase with increasing bicarbonate concentration.

In this communication, the rate and extent of uranyl dissolution was measured from three Hanford vadose zone sediments that had been contaminated by a high level nuclear waste discharge over 50 years ago. The uranium in the sediments existed as discontinuous particle coatings and intragrain precipitates of uranyl silicates primarily in plagioclase-containing clast fragments (McKinley et al., 2002; Wang et al., 2004). Our objectives were to quantify physical, mineralogic, chemical, and thermodynamic factors controlling $U$ release to the aqueous phase. Dissolution was studied over a range of $\mathrm{pH}$ and electrolyte concentration representative of the calcareous geochemical environment from which the samples were obtained. A kinetic model involving carbonate-mediated dissolution kinetics and diffusion from intragrain fracture domains was developed to provide insights on factors controlling the slow observed release rates and incomplete extent of $U$ dissolution from the three sediments.

\section{MATERIALS AND METHODS}

\subsection{Contaminated Sediments}

Uranium-contaminated sediments were obtained from a borehole (299-E33-45) at the Hanford BX tank farm that was drilled through a vadose zone waste plume proximate to tank BX-102 in 2001 to provide information on the depth distribution and inventory of uranium and technetium (Serne et al., 2002). The sediments selected for study are multilithologic and sand-textured, and originated in the Pleistocene catastrophic flood deposits of the Hanford formation. The sediments consist of $48 \%$ quartz, feldspar, and mica, $2 \%$ fines including expansible phyllosilicates. Over $50 \%$ of the sediment is basaltic lithic fragments (Serne et al., 2002).
An estimated $350 \mathrm{~m}^{3}$ of waste solution containing over $7000 \mathrm{~kg}$ of $\mathrm{U}(\mathrm{VI})$ was discharged to the vadose zone in 1951 in the BX tank farm as a result of the overfilling of tank BX-102. This aqueous solution contained nominal concentrations of 2.5 to $5 \mathrm{~mol} / \mathrm{L} \mathrm{Na}_{2} \mathrm{CO}_{3}, 0.36$ $\mathrm{mol} / \mathrm{L} \mathrm{PO}_{4}$, and virtually all fission products of uranium except plutonium with $\mathrm{pH}$ of approximately 10 (Jones et al., 2001). Characterization of the vadose zone near tank BX-102 has defined an extensive plume containing cesium, uranium, and other contaminants. The uranium was most abundant at depths between 21 and $52 \mathrm{~m}$ below ground surface (bgs) in borehole 299-E33-45 (Fig. 1). The maximum concentration of ${ }^{238} \mathrm{U}$ was $1649 \mu \mathrm{g} / \mathrm{g}$. The studied samples were from three depths in the borehole: I53 (36 m bgs), I61 (40 m bgs), and I67 (43 m bgs) with total uranium concentrations ranging from 112 to $404 \mu \mathrm{g} / \mathrm{g}$ (Table 1). There were no significant differences in moisture content and major element concentrations between the samples (Table 1). The water saturation of the samples was calculated to be 16 to $21 \%$ of the sediment porosity assuming solid density of $2.67 \mathrm{~g} / \mathrm{cm}^{3}$ and sediment porosity of 0.32 .

\subsection{Pore-Water Analyses and Modeling}

Chemical analyses of pore waters (Table 2) from unsaturated vadose zone sediments (I55, I61, and I64, Fig. 1) proximate to the three contaminated sediments (I53, I61, and I67) were obtained from Serne et al. (2002). These pore waters were obtained by ultracentrifugation in an unsaturated flow apparatus (UFA). The ultracentrifugation process is a relatively complicated one that is not free of artifacts. Briefly, core sediments were removed from the split spoon sampler, and were homogenized and packed into a UFA Teflon cell of approximate 35 $\mathrm{cm}^{3}$ volume. The cell was spun over $5000 \mathrm{rcf}$ for $8 \mathrm{~h}$ to yield a small volume of pore water. The $\mathrm{pH}$ and ion composition of the pore water were measured by accepted techniques (Serne et al., 2002). Precautions were not taken to prevent $\mathrm{CO}_{2}$ degassing.

The reported chemical analyses were subject to aqueous speciation and saturation state analyses using the MINTEQA2 code (Allison et al., 1998) and a thermodynamic data base assembled by us from the literature. The reported analyses yielded an acceptable anion-cation balance, but the computed speciation was in gross supersaturation with
B-BX-BY tank farm

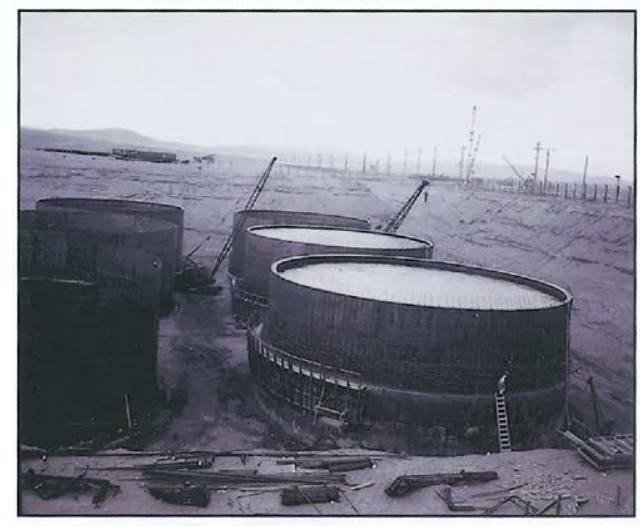

Borehole 299-E33-45

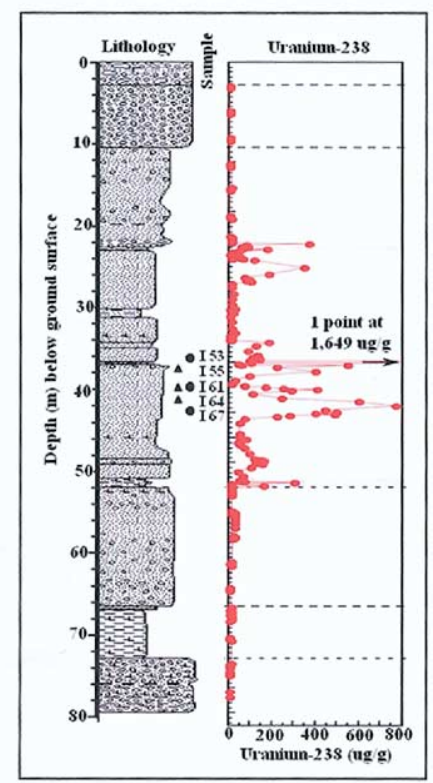

Fig. 1. The photograph (left plot) shows the BX tank farm under construction. Tank BX-102 is the middle on the right. The right plot shows the distribution of uranium in Borehole 299-E33-45 (near Tank BX-102). The collection depths for the sediment (circle) and pore water (triangle) samples are noted at $35-45 \mathrm{~m}$. The borehole was located approximately $9 \mathrm{~m}$ to the right of $\mathrm{BX}-102$. 
Table 1. Sediment characterization. ${ }^{\text {a }}$

\begin{tabular}{|c|c|c|c|c|c|c|c|c|c|}
\hline \multirow[b]{2}{*}{ Sediment } & \multicolumn{5}{|c|}{$\mathrm{g} / 100 \mathrm{~g}$} & \multicolumn{3}{|c|}{$\mu \mathrm{mol} / \mathrm{g}$} & \multirow{2}{*}{$\frac{\mathrm{g} / 100 \mathrm{~g}}{\text { Moisture content }}$} \\
\hline & $\mathrm{Al}$ & $\mathrm{Si}$ & $\mathrm{K}$ & $\mathrm{Ca}$ & $\mathrm{Fe}$ & $\mathrm{U}$ & $\mathrm{Sr}$ & $\mathrm{Mn}$ & \\
\hline I53 & 6.51 & 32.7 & 2.11 & 2.9 & 3.54 & 0.47 & 4.37 & 12.16 & 2.80 \\
\hline I61 & 6.59 & 32.9 & 2.07 & 2.9 & 3.64 & 1.70 & 4.53 & 12.45 & 3.63 \\
\hline I67 & 6.52 & 32.7 & 2.04 & 2.86 & 3.23 & 1.37 & 4.55 & 9.83 & 2.75 \\
\hline
\end{tabular}

${ }^{a} \mathrm{U}$ concentration was measured by X-ray florescence (XRF). Other data from Serne et al., (2002).

respect to calcite. Hanford vadose zone pore waters and groundwaters are invariably in equilibrium with calcite that exists as a minor mineralogic component of all subsurface sediments. MINTEQA2 calculations were then performed to identify the $\mathrm{pH}$ by trial-and-error that yielded calcite equilibrium. The identification process started with a trial $\mathrm{pH}$ for a specific pore-water sample (e.g., I55, I61, or I64 in Table 2). The trial $\mathrm{pH}$ and the analytical data for anions and cations including total inorganic carbonate (Table 2) were used by MINTEQA2 to calculate the pore-water speciation, which was used to calculate calcite saturation index $\left[\log \left(\mathrm{IAP} / \mathrm{K}_{\mathrm{sp}}\right)\right.$, where IAP is the ionic activity product and $\mathrm{K}_{\mathrm{sp}}$ is the solubility product of calcite]. If the calculated calcite saturation index was larger than zero a lower $\mathrm{pH}$ was tried at next step and vice versa. This procedure was iterated until a $\mathrm{pH}$ was identified that led to the absolute value of the calculated saturation index of calcite less than 0.001 . The pore-water speciation correspondent to the identified $\mathrm{pH}$ was used to compute the $\mathrm{pCO}_{2}$ in the pore water and the saturation state of various uranyl minerals (Table 2).

The aqueous complexation constants for U(VI) in our database were from (Guillaumount et al., 2003). The species $\mathrm{Ca}_{2} \mathrm{UO}_{2}\left(\mathrm{CO}_{3}\right)_{3}{ }^{0}$ was also included in the calculation with its constant from Kalmykov and Choppin (2000). Free energies of formation for known uranyl silicates $\left(\Delta_{\mathrm{f}} G_{\mathrm{m}}^{\mathrm{o}}\right)$ were tabulated (Table 3) from the literature or were estimated

Table 2. Measured porewater composition and computed $\mathrm{pH}, \mathrm{pCO}_{2}$, and mineral saturation states. ${ }^{\mathrm{a}}$

\begin{tabular}{|c|c|c|c|}
\hline Component & I55 & I61 & I64 \\
\hline $\mathrm{UO}_{2}^{2+}$ & $2.81 \times 10^{-3}$ & $1.85 \times 10^{-3}$ & $1.04 \times 10^{-2}$ \\
\hline $\mathrm{K}^{+2}$ & $1.23 \times 10^{-3}$ & $3.89 \times 10^{-4}$ & $1.46 \times 10^{-3}$ \\
\hline $\mathrm{Na}^{+}$ & $1.35 \times 10^{-1}$ & $5.31 \times 10^{-2}$ & $1.98 \times 10^{-1}$ \\
\hline $\mathrm{Ca}^{2+}$ & $9.53 \times 10^{-4}$ & $7.11 \times 10^{-4}$ & $4.02 \times 10^{-3}$ \\
\hline $\mathrm{Mg}^{2+}$ & $1.16 \times 10^{-3}$ & $1.90 \times 10^{-4}$ & $5.80 \times 10^{-4}$ \\
\hline $\mathrm{Cl}^{-}$ & $1.58 \times 10^{-3}$ & $4.51 \times 10^{-4}$ & $3.41 \times 10^{-3}$ \\
\hline $\mathrm{NO}_{3}^{-}$ & $3.35 \times 10^{-2}$ & $5.69 \times 10^{-3}$ & $6.34 \times 10^{-2}$ \\
\hline $\mathrm{SO}_{4}^{2-}$ & $1.56 \times 10^{-2}$ & $2.62 \times 10^{-3}$ & $3.39 \times 10^{-2}$ \\
\hline $\mathrm{PO}_{4}^{3-}$ & $3.45 \times 10^{-3}$ & $1.63 \times 10^{-3}$ & $2.32 \times 10^{-4}$ \\
\hline $\mathrm{H}_{4} \mathrm{SiO}_{4}$ & $3.74 \times 10^{-4}$ & $7.16 \times 10^{-4}$ & $3.21 \times 10^{-4}$ \\
\hline $\mathrm{HCO}_{3}{ }^{-}$ & $7.21 \times 10^{-2}$ & $4.11 \times 10^{-2}$ & $6.53 \times 10^{-2}$ \\
\hline $\mathrm{pH}_{\mathrm{m}}$ & 9.35 & 9.06 & 9.16 \\
\hline $\mathrm{pH}_{\mathrm{c}}$ & 7.08 & 7.30 & 6.96 \\
\hline $\mathrm{pCO}_{2 \mathrm{c}}$ & -0.63 & -1.07 & -0.81 \\
\hline$(\mathrm{A}-\mathrm{C})_{\mathrm{a}}(\%)$ & 19.5 & 24.3 & 6.68 \\
\hline$(\mathrm{A}-\mathrm{C})_{\mathrm{s}}(\%)$ & 0.33 & 0.59 & 0.95 \\
\hline SI: Uranophane & -4.49 & -2.37 & -1.97 \\
\hline SI: Na-boltwoodite & -1.33 & -0.60 & -0.12 \\
\hline SI: Soddyite & -5.62 & -4.19 & -3.23 \\
\hline SI: Weeksite & -24.31 & -22.33 & -22.21 \\
\hline SI: Na-Weeksite & -5.85 & -3.65 & -3.57 \\
\hline SI: $\mathrm{SiO}_{2(\mathrm{am})}$ & -0.75 & -0.51 & -0.80 \\
\hline
\end{tabular}

a Solute data (mol/L) from (Serne et al., 2002); $\mathrm{pH}_{\mathrm{m}}, \mathrm{pH}_{\mathrm{c}}$, and $\mathrm{pCO}_{2 \mathrm{c}}$ are the measured $\mathrm{pH}$, computed $\mathrm{pH}$, and computed $\mathrm{CO}_{2}$ partial pressure $(\mathrm{atm})$, respectively (see text); $(\mathrm{A}-\mathrm{C})_{\mathrm{a}}(\%)$ and $(\mathrm{A}-\mathrm{C})_{\mathrm{s}}(\%)$ are the percentage differences between total anion and cation equivalents for the analytical solutes with the measured $\mathrm{pH}$ and after speciation calculation using the calculated $\mathrm{pH}\left({ }_{\mathrm{p}} \mathrm{H}_{\mathrm{c}}\right)$, respectively. SI is the mineral saturation index $\left[\log \left(\mathrm{IAP} / \mathrm{K}_{\mathrm{sp}}\right)\right]$. using the regression method of Chen et al. (1999). The free energies and solubilities of the uranyl silicates have not been well studied. The literature and calculated values were used along with those for other component species from Guillaumount et al. (2003) to calculate equilibrium solubility constants for the uranyl silicates (Table 3 ).

\subsection{Electrolyte Preparation}

Sodium nitrate/bicarbonate solutions ranging between $\mathrm{pH}=7$ to 9.5 with ionic strength (I) $=0.05$ and in equilibrium with atmospheric $\mathrm{CO}_{2}(\mathrm{~g})$ were synthesized by appropriate additions of $\mathrm{NaNO}_{3}, \mathrm{NaHCO}_{3}$, $\mathrm{NaOH}$, or $\mathrm{HNO}_{3}$ (Table 4). The electrolytes were purged with air for at least 1 week to attain carbon dioxide equilibrium with slight $\mathrm{pH}$ adjustments to attain the desired $\mathrm{pH}$ values (e.g., $\mathrm{pH}$ increments of 0.5 $\mathrm{pH}$ unit). Electrolyte $\mathrm{pH}$ was stable after this time period. A similar set of electrolyte solutions ranging from $\mathrm{pH} 7.0$ to 9.0 was made to be in equilibrium with calcite $\left(\mathrm{CaCO}_{3}\right)$ from $\mathrm{Ca}\left(\mathrm{ClO}_{4}\right)_{2}, \mathrm{NaHCO}_{3}, \mathrm{Na}_{2} \mathrm{CO}_{3}$, $\mathrm{NaOH}$, or $\mathrm{HClO}_{4}$, and $\mathrm{CaCO}_{3(\mathrm{~s})}$ (Table 4). These solutions were open to the atmosphere and were allowed to equilibrate with $\mathrm{CaCO}_{3(\mathrm{~s})}$ for over 12 months. The calcite-equilibrated solutions had stable $\mathrm{pH}$ and were filtered through $0.22 \mu \mathrm{m}-\mathrm{GV}$ Millipore filters to remove solidphase calcite before use in dissolution experiments.

\subsection{Dissolution Kinetics}

The time-dependent dissolution of $\mathrm{U}(\mathrm{VI})$ was studied at initial $\mathrm{pH}$ values of 7.5 and 9.5 in the $\mathrm{Na}-\mathrm{NO}_{3}-\mathrm{HCO}_{3}$ and $\mathrm{Na}-\mathrm{Ca}-\mathrm{ClO}_{4}-\mathrm{HCO}_{3}$ electrolyte solutions at a sediment/solution ratio of $200 \mathrm{~g} / \mathrm{L}$. Replicate samples of field-moist sediments were mixed with the electrolyte solutions in acid-washed Teflon centrifuge tubes. The sediments were not air-dried before experimentation to avoid any changes to U(VI) speciation. The sediment suspensions were agitated in a rotating shaker $(50 \mathrm{rpm})$ at room temperature.

After reaction times ranging from hours to $200 \mathrm{~d}$, the suspensions were removed from the shaker, and were centrifuged at $5000 \mathrm{rcf}$ for 20 min. A $0.2 \mathrm{~mL}$ aliquot of supernatant was removed and acidified with $0.1 \mathrm{~mol} / \mathrm{L} \mathrm{HNO}_{3}$. Extensive pretesting with a variety of filters $(0.1-0.2$ $\mu \mathrm{m})$ and centrifugation speeds documented that the phase separation scheme used above provided aqueous samples free of uranium-containing colloids. The experiment was designed so that repeated sample removal would have little or no change on the solid-to-solution ratio. In practice, this ratio changed by $6 \%$ over the course of the experiment. The acidified centrifuged samples were diluted and analyzed for U(VI) with a Kinetic Phosphorescence Analyzer (KPA) (Chemchek Instrument Inc., Richland, Washington). The detection limit of U(VI) with KPA was $4.9 \mathrm{ng} / \mathrm{L}$. All standards and samples were prepared in 0.1 $\mathrm{mol} / \mathrm{L} \mathrm{HNO}_{3}$ to provide a consistent sample matrix (Sowder et al., 1998). Aqueous samples with known U(VI) concentrations [500 and $1000 \mu \mathrm{g} / \mathrm{L} \mathrm{U}(\mathrm{VI})]$ were used as control samples for each $\mathrm{pH}$ and electrolyte to evaluate the potential adsorption of uranium to the walls of the acid-washed Teflon centrifuge tubes for sediment equilibrations. No such adsorption was observed in any electrolyte during the course of the experiment.

At the end of the dissolution experiment, the suspensions were centrifuged as described before and filtered through prewashed $(30 \mathrm{~mL}$ electrolyte $+2 \mathrm{~mL}$ sample) Centriplus YM-30 centrifugal filters (Millipore, MA), which do not sorb aqueous uranyl. The aqueous phase was analyzed for U(VI) before and after filtration. There was no indication for the presence of suspended uranium-containing colloids. The super- 
Table 3. Free energy of formation and solubility product constants of some uranyl silicates.

\begin{tabular}{|c|c|c|c|}
\hline Solid phase & $\Delta_{\mathrm{f}} G_{\mathrm{m}}^{\mathrm{o}}(\mathrm{kJ} / \mathrm{mol})$ & Dissolution Reaction & $\log \mathrm{K}_{\mathrm{sp}}^{\mathrm{a}}$ \\
\hline Na-Boltwoodite & $-2844.8(\mathrm{M})^{1}$ & $\mathrm{Na}\left[\mathrm{UO}_{2}\left(\mathrm{SiO}_{3} \mathrm{OH}\right)\right]\left(\mathrm{H}_{2} \mathrm{O}\right)_{15}+3 \mathrm{H}^{+}=\mathrm{UO}_{2}^{2+}+\mathrm{Na}^{+}+\mathrm{H}_{4} \mathrm{SiO}_{4}+1.5 \mathrm{H}_{2} \mathrm{O}$ & 5.82 \\
\hline Boltwoodite & $-2814.4(\mathrm{C})^{2}$ & $\mathrm{~K}\left[\mathrm{UO}_{2}\left(\mathrm{SiO}_{3} \mathrm{OH}\right)\right]\left(\mathrm{H}_{2} \mathrm{O}\right)_{1.5}+3 \mathrm{H}^{+}=\mathrm{UO}_{2}^{2+}+\mathrm{K}^{+}+\mathrm{H}_{4} \mathrm{SiO}_{4}+1.5 \mathrm{H}_{2} \mathrm{O}$ & 14.74 \\
\hline Uranophane & $-6192.3(\mathrm{M})^{3}$ & $\mathrm{Ca}\left[\mathrm{UO}_{2}\left(\mathrm{SiO}_{3} \mathrm{OH}\right)\right]_{2}\left(\mathrm{H}_{2} \mathrm{O}\right)_{5}+6 \mathrm{H}^{+}=2 \mathrm{UO}_{2}^{2+}+\mathrm{Ca}^{2+}+2 \mathrm{H}_{4} \mathrm{SiO}_{4}+5 \mathrm{H}_{2} \mathrm{O}$ & 11.70 \\
\hline Soddyite & $-3653.0(\mathrm{M})^{1}$ & $\left(\mathrm{UO}_{2}\right)_{2}\left(\mathrm{SiO}_{4}\right)\left(\mathrm{H}_{2} \mathrm{O}\right)_{2}+4 \mathrm{H}^{+}=2 \mathrm{UO}_{2}^{2+}+\mathrm{H}_{4} \mathrm{SiO}_{4}+2 \mathrm{H}_{2} \mathrm{O}$ & 5.98 \\
\hline Na-Weeksite & $-7993.9(\mathrm{M})^{1}$ & $\mathrm{Na}_{2}\left(\mathrm{UO}_{2}\right)_{2}\left(\mathrm{Si}_{5} \mathrm{O}_{13}\right)\left(\mathrm{H}_{2} \mathrm{O}\right)_{3}+6 \mathrm{H}^{+}+4 \mathrm{H}_{2} \mathrm{O}=2 \mathrm{UO}_{2}^{2+}+2 \mathrm{Na}^{+}+5 \mathrm{H}_{4} \mathrm{SiO}_{4}$ & 4.42 \\
\hline Weeksite & $-7952.7(\mathrm{C})^{2}$ & $\mathrm{~K}_{2}\left(\mathrm{UO}_{2}\right)_{2}\left(\mathrm{Si}_{5} \mathrm{O}_{13}\right)\left(\mathrm{H}_{2} \mathrm{O}\right)_{3}+6 \mathrm{H}^{+}+4 \mathrm{H}_{2} \mathrm{O}=2 \mathrm{UO}_{2}^{2+}+2 \mathrm{~K}^{+}+5 \mathrm{H}_{4} \mathrm{SiO}_{4}$ & 18.84 \\
\hline
\end{tabular}

${ }^{a}$ Solubility product constant $\left(\log \mathrm{K}_{\mathrm{sp}}\right.$ ) was calculated using $\Delta_{\mathrm{f}} G_{\mathrm{m}}^{\mathrm{o}}$ of uranyl species and free energies of auxiliary components from Guillaumount et al. (2003). 1. Measured by Nguyen et al. (1992) and Moll et al. (1996) and recalculated by Chen et al. (1999). 2. Calculated using regression method of Chen et al. (1999). 3. Perez et al. (2000).

natant $\mathrm{pH}$ was immediately measured on a $1 \mathrm{~mL}$ aliquot of the supernatant sample. The supernatant was then acidified and analyzed for other elements (Na, Ca, Mg, Si, P) by ICP-AES. The total inorganic carbon was determined by coulometric titration (ASTM, 1988). The suspensions were also directly filtered through the prewashed filters and the filtrate and moist sediments (retained by the filter) were analyzed by time-resolved laser-induced fluorescence spectroscopy (TRLFS). Corresponding sediment duplicates were washed to remove soluble U(VI) with $2 \mathrm{~mL}$ of deionized water, centrifuged, and air dried for thin section preparations for X-ray microscopic examination.

\subsection{Solubility Measurements}

The contaminated sediments were equilibrated with the full suite of $\mathrm{Na}-\mathrm{NO}_{3}-\mathrm{HCO}_{3}$ and $\mathrm{Na}-\mathrm{Ca}-\mathrm{ClO}_{4}-\mathrm{HCO}_{3}$ solutions (Table 4) at a sediment/solution ratio of $200 \mathrm{~g} / \mathrm{L}$ to determine the solubility of uranium in the sediment samples. After reaction times of 65, 149, and $197 \mathrm{~d}$, the suspensions were sampled, and $\mathrm{U}(\mathrm{VI})$ and $\mathrm{pH}$ were measured as described before. $\mathrm{Na}, \mathrm{Ca}, \mathrm{Mg}, \mathrm{Si}, \mathrm{P}$, and inorganic $\mathrm{C}$ were determined on the aqueous samples collected at $197 \mathrm{~d}$.

\subsection{Dissolution in Ammonium Carbonate Solution}

A strong uranyl complexant $\left[0.5 \mathrm{~mol} / \mathrm{L}\left(\mathrm{NH}_{4}\right)_{2} \mathrm{CO}_{3}\right.$ ) (Duff et al., 2002)] was used to expedite the rate and extent of uranium dissolution. After solubility measurements at $\mathrm{pH} 7.0$ (section 2.5), the sediment was washed twice with and placed in $0.5 \mathrm{~mol} / \mathrm{L}\left(\mathrm{NH}_{4}\right)_{2} \mathrm{CO}_{3}$ at $\mathrm{pH} 8.4$ with a suspension concentration of $200 \mathrm{~g} / \mathrm{L}$. Replicate suspensions were centrifuged for phase separation at selected times up to $450 \mathrm{~h}$, and the supernatant $\mathrm{U}(\mathrm{VI})$ and $\mathrm{pH}$ were measured. The aqueous concentrations

Table 4. Chemical compositions of electrolytes used in uranium dissolution experiments. ${ }^{\text {a }}$

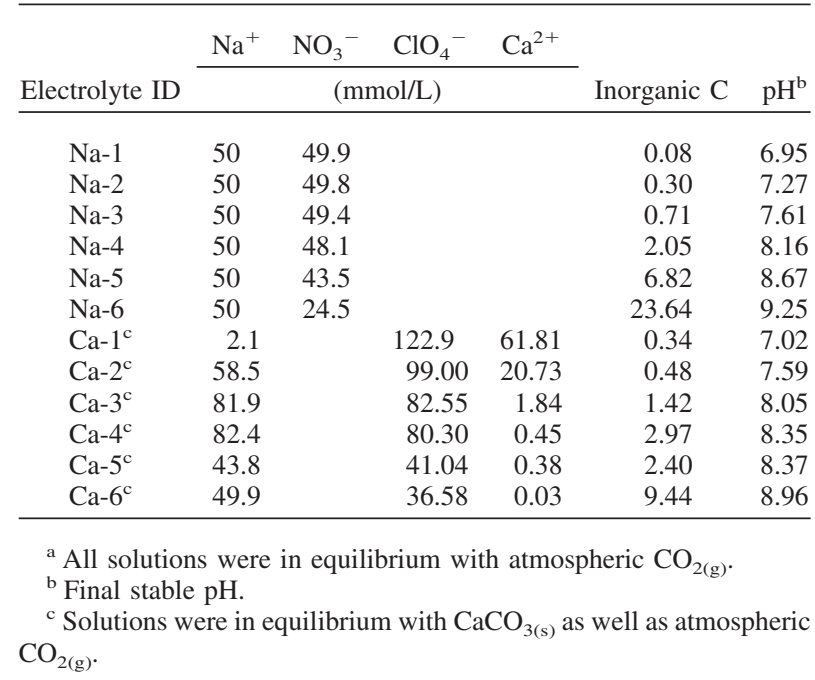

of $\mathrm{Na}, \mathrm{Ca}, \mathrm{Mg}, \mathrm{Si}, \mathrm{P}$, and inorganic $\mathrm{C}$ were measured after $450 \mathrm{~h}$ of equilibration.

\subsection{Spatial Distribution of Uranyl Phases}

Thin sections of the contaminated sediments were prepared and analyzed by scanning electron microscopy (SEM), electron microprobe (EMP), and X-ray microprobe (XRM). A few $\mathrm{g}$ of sediment was imbedded in epoxy, wafered, affixed to a quartz slide, and polished for petrographic examination. Samples for SEM were carbon-coated for conductivity. The EMP and SEM analyses were combined as necessary to provide compositional and morphologic information concerning the occurrence and associations of uranium-bearing phases. Samples were examined using an accelerating potential of $20 \mathrm{keV}$, and compositional information was collected using either wavelength-dispersive (WDS) or energy dispersive spectrometers (EDS).

$\mathrm{X}$-ray microprobe (XRM) measurements were performed at the Pacific Northwest Consortium-Collaborative Access Team (PNCCAT) insertion device beamline (Heald et al., 1999) at the Advanced Photon Source (APS) at Argonne National Laboratory. Thin sections were mounted to an open stepper motor-driven stage on an optical bench and moved relative to the X-ray beam, which was focused by Kirkpatrick-Baez mirrors to a diameter of $6 \mu \mathrm{m}$ on the sample surface. The X-ray flux was $\sim 5 \times 10^{11}$ photons $/ \mathrm{sec}$. False-color (blue to red) abundance maps were constructed for selected areas after normalizing detected X-rays to a measured current that was proportional to the primary flux. Fluorescent element-characteristic X-rays were detected with either WDS or EDS. Digital EMP, SEM, and XMP images were manipulated and merged using Photoshop (Adobe Systems).

\section{RESULTS}

\subsection{Thermodynamic Calculations}

Calculations using MINTEQA2 indicated that the reported $\mathrm{pH}$ of the displaced pore waters (Table 2) was inconsistent with the constraint of in-ground pore-water equilibrium with calcite and that $\mathrm{CO}_{2}(\mathrm{~g})$ degassed during the pore water extraction, manipulation, and analysis procedures. The computed $\mathrm{pH}$ 's of the pore waters had to be reduced to approximately $\mathrm{pH} \approx 7$ to yield equilibrium with calcite. The computed $\mathrm{pCO}_{2}$ values for these pore waters were quite high atm, $(\approx 0.1$ Table 2$)$. These high partial pressures of $\mathrm{CO}_{2}(\mathrm{~g})$ apparently resulted from waste-sediment reaction that involved the ion exchange displacement of adsorbed $\mathrm{Ca}^{2+}$ by high $\mathrm{Na}^{+}$in the waste solution and the resulting precipitation of calcite that lowered $\mathrm{pH}$. The lower $\mathrm{pH}$ induced offgassing of $\mathrm{CO}_{2}(\mathrm{~g})$ from the waste solution that contained large concentrations of bicarbonate and carbonate.

The aqueous speciation of U(VI) in the pore waters and saturation states with respect to uranyl silicates were computed using our aqueous U(VI) speciation database and solubility 
reactions in Table 3 along with the computed $\mathrm{pH}$ values. The aqueous species $\mathrm{UO}_{2}\left(\mathrm{CO}_{3}\right)_{3}{ }^{4-}$ accounted for greater than $78 \%$ of the dissolved $\mathrm{U}$ in all of the pore waters, with the remainder occurring as $\mathrm{Ca}_{2} \mathrm{UO}_{2}\left(\mathrm{CO}_{3}\right)_{3}{ }^{0}$ and $\mathrm{UO}_{2}\left(\mathrm{CO}_{3}\right)_{2}{ }^{2-}$. Aqueous species of U(VI) involving silicate, phosphate, hydroxide, chloride, and sulfate were minimal. The saturation index (log IAP/ $\mathrm{K}_{\mathrm{sp}}$ ) with respect to Na-boltwoodite was closest to the equilibrium value of 0 among all of the uranyl silicates. However, Na-boltwoodite was consistently undersaturated in the pore water as was amorphous silica $\left[\mathrm{SiO}_{2}(\mathrm{am})\right]$.

\subsection{Nature of Sediment Uranium}

Uranium in Hanford sediment was found to be distributed as discrete precipitates within interiors of sediment grains (Fig. 2).
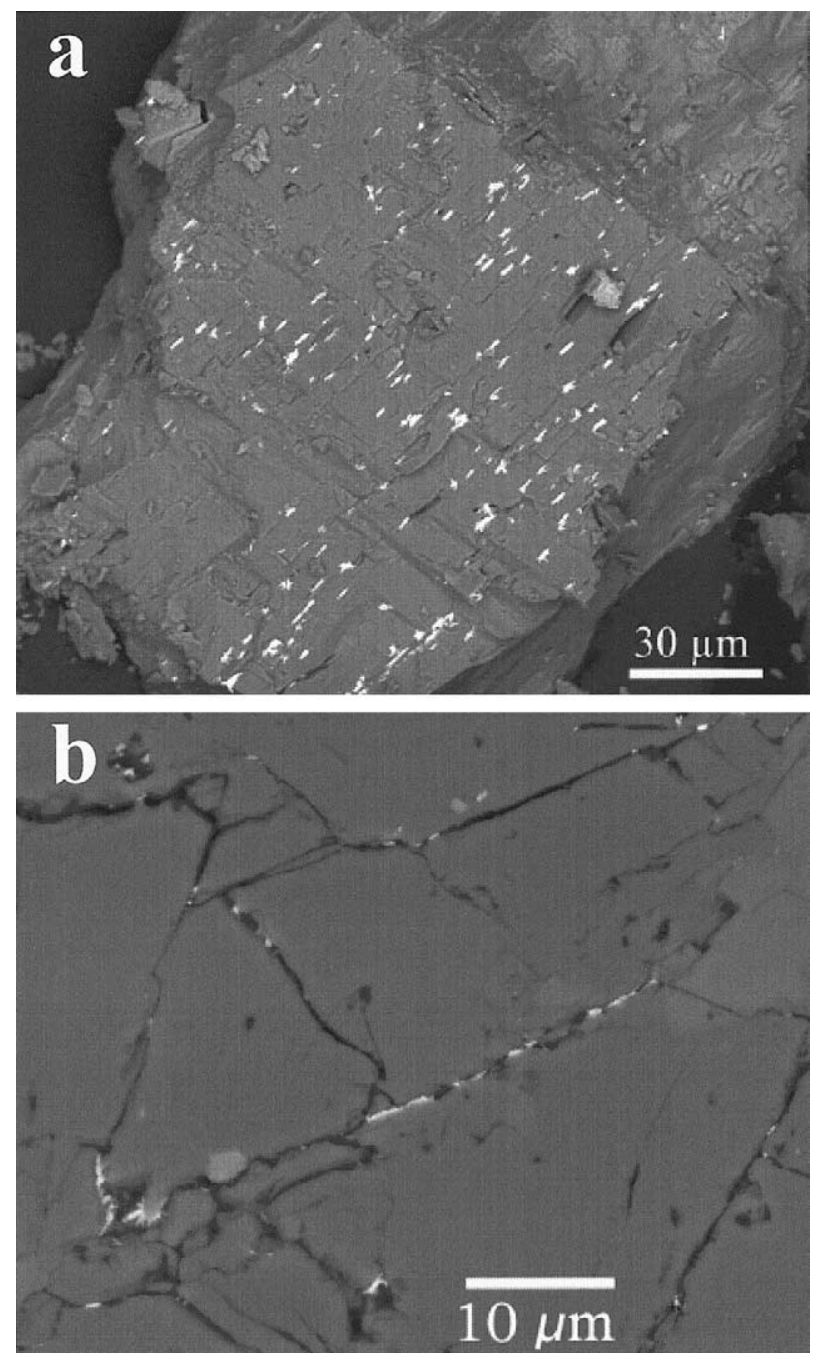

Fig. 2. Back-scattered-electron SEM images of sample I61 showing intraparticle uranium distribution within a plagioclase feldspar grain. Electron dense U(VI) precipitates appear white in the images. Image a) shows U(VI) crystallites that are aligned in parallel with cleavages on an intraparticle surface that was obtained by pressure-splitting the feldspar grain along a microfracture plane. Image b) shows U(VI) precipitates within microfractures in a thin section that was cut perpendicular to the fracture face in image a).
The precipitates were sparse on particle surfaces and were more abundant within microfractures of granitic lithic fragments, e.g., plagioclase feldspar (a minor component of the overall lithic fragment population) (McKinley et al., 2002). The precipitates were minute, generally less than $3 \mu \mathrm{m}$ across, occurring as fine acicular crystals, in either radiating or parallel arrays in microfractures (Fig. 2). The precipitates were primarily aligned with two planes of microfractures meeting at or near 90 degree angles, consistent with two planes of plagioclase cleavage. The precipitates were distributed in microfractures of variable width and length.

$\mathrm{X}$-ray adsorption near edge spectroscopy (XANES) indicated that only $\mathrm{U}(\mathrm{VI})$ was present in the sediment (Catalano et al., 2004; McKinley et al., 2002). Detailed analyses of both extended X-ray absorption fine structure (Catalano et al., 2004) and laser-induced fluorescence spectroscopy (Wang et al., 2004) indicated that the precipitates were uranyl silicates, most likely Na-boltwoodite or uranophane. The compositional analysis by energy dispersive X-ray spectroscopy (McKinley et al., 2002) also indicated that the precipitates were uranyl silicates, but likely Na-boltwoodite, Na-weeksite, or soddyite. The distinct fluorescence emission spectra of the sediment $U$ was measured at liquid He temperature and its life-time did not change during dissolution (Wang et al., 2004). The presence of a single U-silicate phase was therefore implied within the sediment.

\subsection{Uranium Solubility}

The sediment uranyl-silicate phase dissolved to yield aqueous U(VI) concentrations of 8.4 to $231 \mu \mathrm{mol} / \mathrm{L}$ after $197 \mathrm{~d}$ of equilibration (Fig. 3). Dissolved U(VI) displayed two distinct regions: a constant concentration region below $\mathrm{pH} 8.2$ and a region of increasing dissolved $\mathrm{U}(\mathrm{VI})$ above that $\mathrm{pH}$. The uranyl concentrations varied significantly between the different samples, but the variation was insignificant between $\mathrm{Na}_{-} \mathrm{NO}_{3}-$ $\mathrm{HCO}_{3}$ and $\mathrm{Na}-\mathrm{Ca}-\mathrm{ClO}_{4}-\mathrm{HCO}_{3}$ electrolytes. The uranyl concentration in the constant region $(\mathrm{pH}<8.2)$ was approximately 13-42 $\mu \mathrm{mol} / \mathrm{L}$ and followed the sample order of I61 $>$ I67 $>$ I53. Above $\mathrm{pH} 8.5$, dissolved U(VI) followed the sample order of I67 $>$ I61 $>$ I53. The concentrations of $\mathrm{Na}$ and/or $\mathrm{Ca}$ in the sediment suspensions at the end of equilibration (Appendix A, Tables A1 and A2) were only slightly different from those in the electrolytes (Table 4), indicating no significant dissolution or precipitation of sediment components during experimentation. Small changes were noted to suspension $\mathrm{pH}$ that resulted from the initial inequality in sediment and electrolyte $\mathrm{pH}$ values.

Uranyl speciation in the suspensions indicated that the increase of dissolved $\mathrm{U}$ above $\mathrm{pH} 8.2$ was consistent with increasing $\mathrm{UO}_{2}\left(\mathrm{CO}_{3}\right)_{3}{ }^{4-}$ concentration. The uranyl solubilities in the sediment suspensions were computed for Na-boltwoodite, uranophane, and several other plausible U phases (Fig. 3 and Appendix B, Tables B1 and B2). The calculations assumed that uranyl was congruently dissolved from only one phase (e.g., Na-boltwoodite, or uranophane, or other) and were made using the measured solution compositions at the end of equilibration (Appendix A, Tables A1 and A2). The total solid U(VI) concentrations available for dissolution were assumed to equal the total $\mathrm{U}$ content of the sediment (Table 1). Given the relatively 

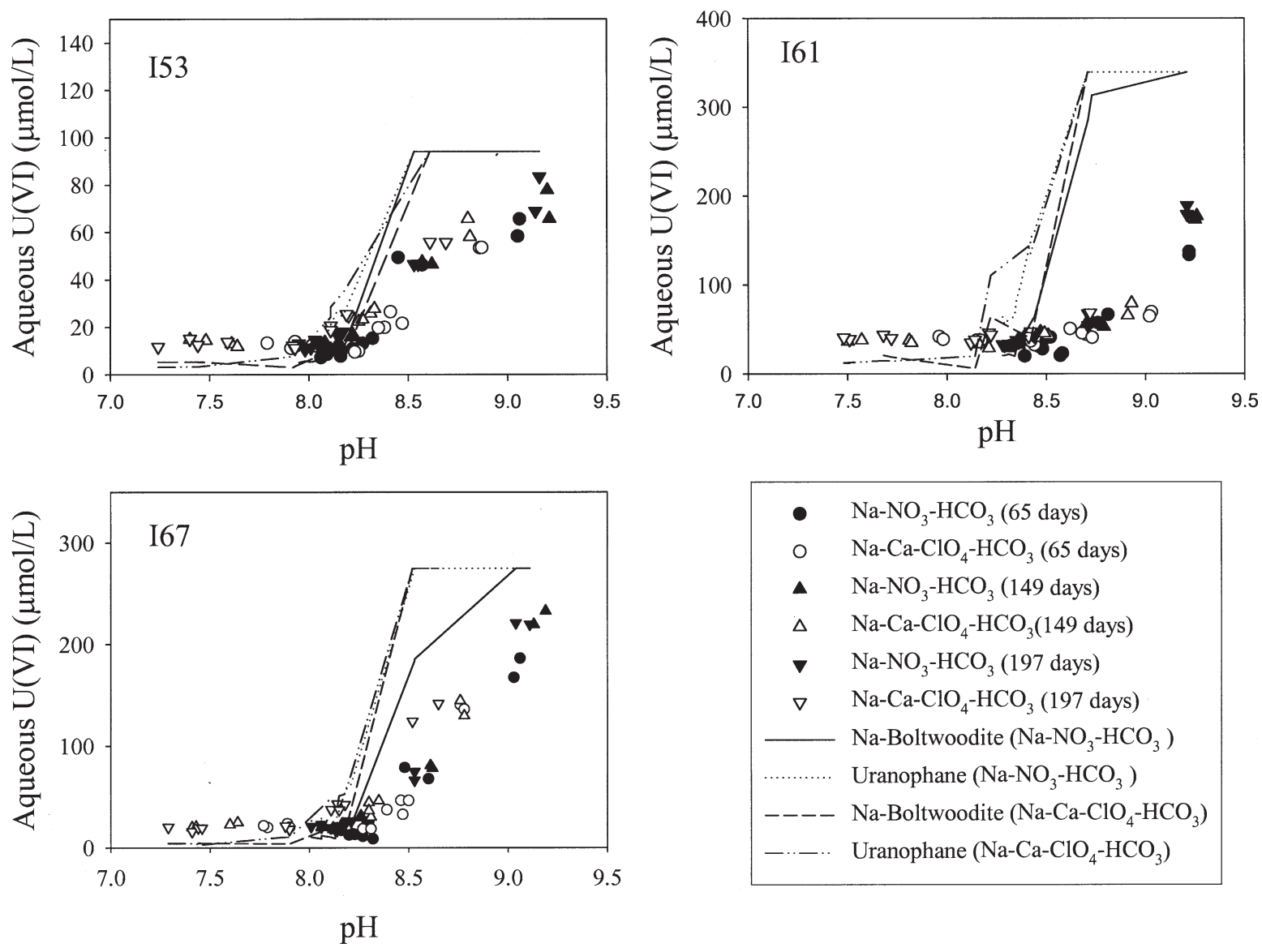

Fig. 3. Measured dissolved uranyl (symbols) and calculated uranyl solubility (lines) for samples I53, I61, and I67 in $\mathrm{Na}-\mathrm{NO}_{3}-\mathrm{HCO}_{3}$ and $\mathrm{Na}-\mathrm{Ca}-\mathrm{ClO}_{4}-\mathrm{HCO}_{3}$ electrolytes with a sediment/water ratio of $200 \mathrm{~g} / \mathrm{L}$. Calculated solubilities are shown for Na-boltwoodite and uranophane.

low $\mathrm{U}_{\mathrm{TOT}}$ in the sediments, the sediment $\mathrm{U}$ was computed to completely dissolve above $\mathrm{pH} 8.5$ (e.g., horizontal line segments: Fig. 3, solid, dashed, dotted, and dot-dashed lines).

\subsection{Uranyl Dissolution Kinetics}

The rate of sediment $\mathrm{U}$ dissolution showed marked $\mathrm{pH}$ dependence and varied between sediments (Fig. 4). Uranyl concentrations increased slowly with time in the electrolytes with lower $\mathrm{pH}(<7.6)$ (Fig. 4) (the corresponding suspension $\mathrm{pH}$ values after $\sim 200 \mathrm{~d}$ of dissolution are given in Appendix A, Tables A3 and A4). The measured uranyl concentrations at $200 \mathrm{~d}$ were consistent with those observed in the solubility experiments (Fig. 3). The U(VI) dissolution rate was higher near $\mathrm{pH}$ 9, and the overall release rate decreased with increasing equilibration time. The electrolyte composition did not appear to influence the dissolution rate. The leached uranium at $\mathrm{Ph} \approx 9.0$ represented 93,57 , and $90 \%$ of the total uranium in sediments I53, I61, and I67, respectively, after $200 \mathrm{~d}$ of contact with $\mathrm{Na}-\mathrm{NO}_{3}-\mathrm{HCO}_{3}$ and $\mathrm{Na}-\mathrm{Ca}-\mathrm{ClO}_{4}-\mathrm{HCO}_{3}$ electrolytes.

The sediments displayed a rapid initial release of U(VI) in the suspensions near $\mathrm{pH} 9$ (Fig. 4). The total U concentration released in this initial event for sediments I53 and I67 equaled that present in the pore water after adjusting for dilution by the added electrolyte solutions. The diluted U(VI) concentration was estimated to be $4.29,13.43$, and $8.99 \mu \mathrm{mol} / \mathrm{L}$ for samples I53, I61, and I67, respectively. The initial release of U(VI) from I61 was about double that attributable to pore water, suggesting the desorption of adsorbed U(VI) from the sediment at higher $\mathrm{pH}$.

\subsection{Uranium Dissolution in $\left(\mathrm{NH}_{4}\right)_{2} \mathrm{CO}_{3}$ Electrolyte}

We suspected that uranyl release could be limited by the inaccessibility of microprecipitates in internal microfractures, and associated mass transfer limitation imposed on solute movement to and from these locations. Ammonium carbonate $\left(\left(\mathrm{NH}_{4}\right)_{2} \mathrm{CO}_{3}, 0.5 \mathrm{~mol} / \mathrm{L}\right)$ has been used as an extractant of U(VI) from sediments (Duff et al., 1998, 2000). It was used here to expedite $\mathrm{U}(\mathrm{VI})$ dissolution and its mass transfer rate from intraparticle regions. The rate of uranyl release (Fig. 5) by $\left(\mathrm{NH}_{4}\right)_{2} \mathrm{CO}_{3}$ increased by factors of 15 or more as compared to $\mathrm{Na}-\mathrm{NO}_{3}-\mathrm{HCO}_{3}$ and $\mathrm{Na}-\mathrm{Ca}-\mathrm{ClO}_{4}-\mathrm{HCO}_{3}$ electrolytes (Fig. 4). Mass balance calculations indicated the release of 100, 69, and $93 \%$ of total uranium from sediments I53, I61, and I67, respectively. U release from sample I61 again showed a slow rate compared with the two other sediments. The suspension $\mathrm{pH}$ increased slowly from 8.4 to 9 (data not shown). The aqueous 

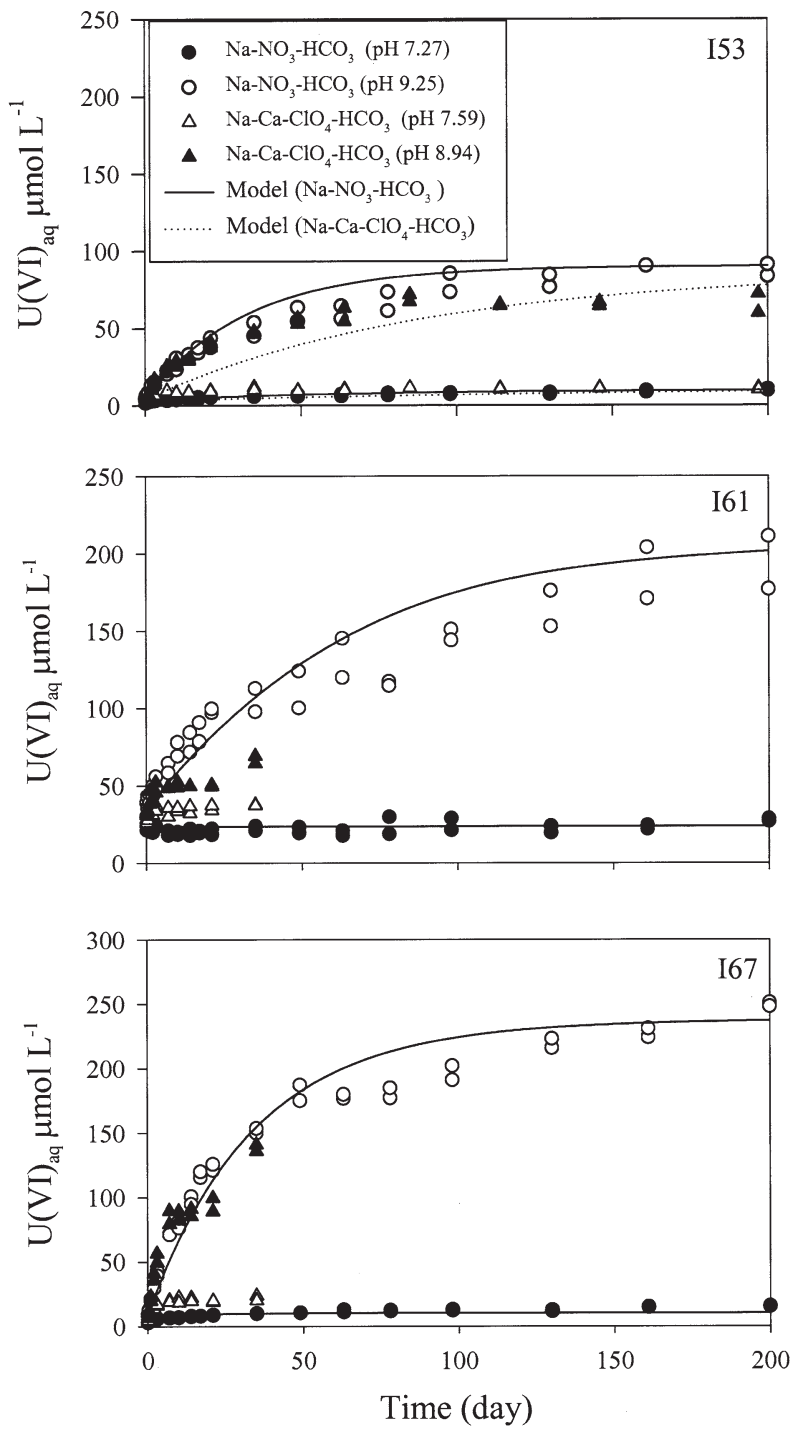

Fig. 4. Time-dependent dissolution of U(VI) from $\mathrm{BX}-102$ sediments in $\mathrm{Na}-\mathrm{NO}_{3}-\mathrm{HCO}_{3}$ and $\mathrm{Na}-\mathrm{Ca}-\mathrm{ClO}_{4}-\mathrm{HCO}_{3}$ electrolytes with a sediment/ water ratio of $200 \mathrm{~g} / \mathrm{L}$. Symbols and lines are experimental and modeling results, respectively. The electrolyte $\mathrm{pH}$ values are given in the figure legend. The corresponding suspension $\mathrm{pH}$ values after $200 \mathrm{~d}$ of dissolution are given in Tables A3 and A4 of Appendix A.

silicate, sodium, magnesium, and calcium concentrations were all higher after $19 \mathrm{~d}$ (Appendix A, Table A5), as a result of ion exchange and dissolution reactions.

\section{DISCUSSION}

\subsection{Solubility of Uranyl Microprecipitates}

Spectroscopic and microscopic studies collectively indicated that the sediment uranium phases were uranyl silicates, most likely uranophane group minerals or possibly soddyite or weeksite. X-ray absorption (Catalano et al., 2004) and laser fluorescence (Wang et al., 2004) analyses of the sediments indicated the presence of only one uranyl silicate phase in all of these sediments that remained unchanged with dissolution. Although
Na-boltwoodite and uranophane most closely matched the spectroscopic results, the specific uranyl phase was not resolved because of the similar crystal structures of uranophane group minerals. Electron microprobe measurements of the composition of the uranyl silicate (McKinley et al., 2002) were not sufficiently precise to allow phase identification.

The measured uranyl concentrations in the batch solubility experiments were closest to the computed solubilities of $\mathrm{Na}$ boltwoodite and uranophane (Fig. 3, Appendix A, Tables A1 and A2 and Appendix B, Tables B1 and B2), but significant differences existed. The computed pore water was close to saturation with to Na-boltwoodite (Table 2). The uranophane solubility was computed from a solubility constant $\left(\log \mathrm{K}_{\mathrm{sp}}\right)$ of 11.7 (Table 3), which was an average of the values measured for synthetic uranophane in bicarbonate solutions (10.75-12.94; Perez et al., 2000). A value of $9.42( \pm 0.48)$ was reported for synthetic uranophane in $\mathrm{Na}-\mathrm{ClO}_{4}$ electrolyte (Nguyen et al., 1992). The computation of Na-boltwoodite solubility used a log $\mathrm{K}_{\mathrm{sp}}$ value of 5.82 , which was reported as $\geq 5.82( \pm 0.16)$ in $\mathrm{Na}_{-} \mathrm{ClO}_{4}$ electrolyte because of the formation of secondary soddyite during dissolution (Nguyen et al., 1992).

The disparity between the computed solubility of sediment $\mathrm{U}$ as either Na-boltwoodite or uranophane and the measured uranyl concentrations above pH 8.2 (Fig. 3) implied that the sediment U-silicate had not yet achieved dissolution equilibrium after $197 \mathrm{~d}$ of equilibration. This conclusion was supported by i.) the kinetic data in Figure 4 that showed continued dissolution of $U$ (primarily from sediments I61 and I67) for $200 \mathrm{~d}$ without the attainment of steady-state concentration values and ii.) a lower than expected increase (e.g., slope) in measured uranyl concentration with increasing $\mathrm{pH}$ (Fig. 3). As a result of this apparent disequilibrium, the measured uranyl data did not allow for defensible evaluation as to whether the U-silicate free energies in Table 3 were or were not descriptive of the sediment $\mathrm{U}$ phase. The observation that $\left(\mathrm{NH}_{4}\right)_{2} \mathrm{CO}_{3}$ accelerated the release rate by factors of 15 or more (Figs. 4 and 5) implied that the kinetic dissolution rate of the U-silicate or mass transfer prevented the attainment of equilibrium above $\mathrm{pH}$ 8.2. The relative importance of these processes was tested

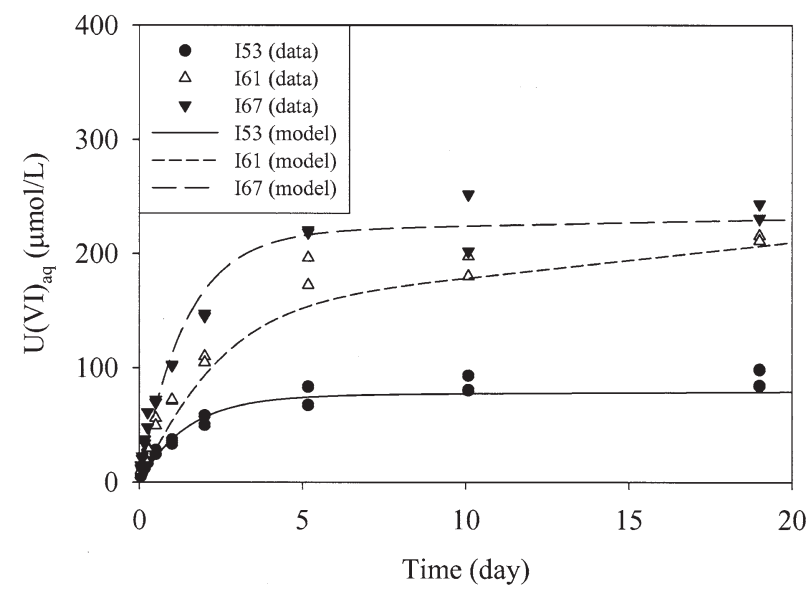

Fig. 5. Time-dependent dissolution of U(VI) from BX-102 sediments in $0.5 \mathrm{~mol} / \mathrm{L}\left(\mathrm{NH}_{4}\right)_{2} \mathrm{CO}_{3}$ electrolyte. The sediments were previously contacted with $\mathrm{Na}-\mathrm{Ca}-\mathrm{ClO}_{4}-\mathrm{HCO}_{3}$ electrolyte at $\mathrm{pH} 7.0$ for $197 \mathrm{~d}$ before $\left(\mathrm{NH}_{4}\right)_{2} \mathrm{CO}_{3}$ extraction. 
through kinetic and microscopic transport modeling described in Section 4.3.

The calculated uranyl solubility as either uranophane or Na-boltwoodite was generally lower than the measured values below pH 8.2 (Fig. 3). This result could not be attributed to dissolution kinetics, but could be explained by the variations in $\log \mathrm{K}_{\mathrm{sp}}$ given their large reported ranges. The reaction constants of Na-boltwoodite and uranophane were recalculated using following equations:

for uranophane:

$$
\mathrm{K}_{\mathrm{sp}}=a_{U O_{2}^{2+}}^{2} a_{\mathrm{Ca}^{2}+a_{H_{4}}^{2} \mathrm{SiO}_{4}} a_{H^{+}}^{-6}
$$

for Na-boltwoodite:

$$
\mathrm{K}_{\mathrm{sp}}=a_{U O_{2}^{2+}} a_{\mathrm{Na}^{+}} a_{\mathrm{H}_{4} \mathrm{SiO}_{4}} a_{\mathrm{H}^{+}}^{-3}
$$

where $a_{i}$ is the activity of aqueous species $i$, that was calculated using the analytical data for each sample below $\mathrm{pH} 8.2$ in Figure 3 and Tables A1 and A2. The calculated solubility product $\left(\log \mathrm{K}_{\mathrm{sp}}\right)$ for Na-boltwoodite and uranophane, respectively, were $6.15( \pm 0.06)$ and $11.58( \pm 0.18)$ in $\mathrm{Na}-\mathrm{NO}_{3}-\mathrm{HCO}_{3}$ (sample number $(\mathrm{n})=13)$, and 6.04 $( \pm 0.61)$ and $12.55( \pm 0.80)$ in $\mathrm{Na}-\mathrm{Ca}-\mathrm{ClO}_{4}-\mathrm{HCO}_{3}(\mathrm{n}=28)$ electrolytes. The average values from all samples $(\mathrm{n}=41)$ were $6.08( \pm 0.50)$ and 12.2( \pm 0.8$)$ for Na-boltwoodite and uranophane, respectively. These $\log \mathrm{K}_{\mathrm{sp}}$ values were slightly higher than the literature values, but within the reported ranges.

\subsection{Uranyl Release Processes}

Uranyl dissolution from the contaminated sediments was a kinetic process characterized by an initial fast rate. This behavior could be explained by the coupled dissolution of the precipitates and solute mass transfer from intraparticle space. The pseudo-zero-order initial rates were 3.7, 5.5, 12.5 in $\mathrm{Na}^{-\mathrm{NO}_{3}-}$ $\mathrm{HCO}_{3}$ electrolytes at high pH (Fig. 4) and 5.6, 94.1, and 182.4 $(\mu \mathrm{mol} / \mathrm{L}) / \mathrm{d}$ in $\left(\mathrm{NH}_{4}\right)_{2} \mathrm{CO}_{3}$ (Fig. 5) for samples I53, I61, and I67, respectively. The increase in uranyl mineral dissolution rate with increasing bicarbonate concentration has been observed for uranophane (Perez et al., 2000); soddyite (Perez et al., 1997); uranyl oxyhydroxides including metaschopite and becquerelite (Sowder et al., 2001) and $\mathrm{UO}_{3} \cdot \mathrm{H}_{2} \mathrm{O}$ and $\mathrm{U}_{3} \mathrm{O}_{8}$ (Steward and Mones, 1997); and uranyl phosphate including metaautunite and chernikovite (Sowder et al., 2001). Our results confirmed that the dissolution of the sediment U(VI) phase was promoted by aqueous bicarbonate.

A ligand (bicarbonate)-promoted mechanism has been used to describe uraninite dissolution in carbonate solution (Nicol and Needes, 1977; Hiskey, 1979, 1980; Sharma et al., 1996; Shoesmith et al., 1996a,b, 1989, 1998; Sunder et al., 1997; De Pablo et al., 1999). These studies showed that electron transfer, coordination of carbonate species on surface, and detachment of uranium-carbonate species from the surface were three steps controlling uraninite dissolution. According to these previous studies and our experimental data, we constructed a plausible model of uranyl dissolution from the Hanford sediments:

A. Coordinate carbonate species on U(VI) mineral surface

$$
\equiv \mathrm{U}(\mathrm{VI})+\mathrm{HCO}_{3}^{-} \underset{\mathrm{k}_{-1}}{\stackrel{\mathrm{k}_{1}}{\Leftrightarrow}} \equiv \mathrm{U}(\mathrm{VI})-\mathrm{HCO}_{3}^{-}
$$

B. Detachment of uranyl carbonate species from the mineral surface:

$$
\equiv \mathrm{U}(\mathrm{VI})-\mathrm{HCO}_{3}^{-} \stackrel{\mathrm{k}_{2}}{\Rightarrow} \mathrm{U}(\mathrm{VI})-\mathrm{HCO}_{3(\mathrm{aq})}^{-}
$$

The detached aqueous $\mathrm{U}(\mathrm{VI})$ will rearrange its aqueous speciation in accordance with the solution composition and $\mathrm{pH}$. Assuming that detachment (B) was rate-limiting, a kinetic rate expression from reactions 3 and 4 can be expressed as,

$$
\frac{\mathrm{dU}(\mathrm{VI}) \mathrm{aq}}{\mathrm{dt}}=\mathrm{k}_{2} \mathrm{~K}_{1}[\equiv \mathrm{U}(\mathrm{VI})]\left\{\mathrm{HCO}_{3}^{-}\right\}
$$

where $\mathrm{K}_{1}$ is the equilibrium constant for reaction $3 ; \mathrm{k}_{1}$ and $\mathrm{k}_{-1}$ are the forward and backward kinetic rate constants, respectively for reaction $3 ; \mathrm{k}_{2}$ is the forward rate constant for reaction $4 ;\left\{\mathrm{HCO}_{3}{ }^{-}\right\}$is the activity of $\mathrm{HCO}_{3}{ }^{-}$, and $[\equiv \mathrm{U}(\mathrm{VI})]$ is the surface concentration of uranyl precipitates available for coordination with $\mathrm{HCO}_{3}{ }^{-}$.

Experimental studies of the dissolution kinetics of uranyl minerals in bicarbonate solutions have not uniformly agreed with the model described by Eqns. 3 to 5. The expression 5 predicts that dissolution rate is the first order with respect to bicarbonate activity when uranyl surface coordination sites remain constant. A rate expression proportional to carbonate concentration $\left(\left[\mathrm{HCO}_{3}{ }^{-}\right]^{0.7}\right)$ was obtained for uranophane dissolution in batch and stirred flow systems (Perez et al., 2000). A rate order of 0.65 with respect to total carbonate concentration was observed from a regression analysis of the measured rates of uranyl oxyhydroxide dissolution in bicarbonate solutions (Steward and Mones, 1997). Our observation that the dissolution rate of U(VI) from Hanford sediment increased over 15 times when bicarbonate activity increased 17-20 times was approximately in line with the pseudo-first-order assumption. The regression studies of Perez et al. (2000) and Steward and Mones (1997) found that the influence of $\mathrm{pH}$ was not statistically significant compared with that of carbonate. The rate expression in Eqn. 5 implicitly assumed that the influence of $\mathrm{pH}$ was a result of variable bicarbonate concentration.

The reaction scheme of Eqns. 3 to 5 is appropriate when the solution composition is far from equilibrium. A comparable rate expression for near equilibrium includes an effective "freeenergy" modifying term (e.g., Aagaard and Helgeson, 1982),

$$
\frac{\mathrm{dU}(\mathrm{VI}) \mathrm{aq}}{\mathrm{dt}}=\mathrm{k}^{\prime}[\equiv \mathrm{U}(\mathrm{VI})]\left\{\mathrm{HCO}_{3}^{-}\right\}\left(1-\mathrm{IAP} / \mathrm{K}_{\mathrm{sp}}\right)
$$

where $\mathrm{k}^{\prime}=\mathrm{k}_{2} \mathrm{~K}_{1}$; IAP is the ion activity product; and $\mathrm{K}_{\mathrm{sp}}$ is the solubility constant. Both Eqns. 5 and 6 require a surface site concentration for the dissolving uranyl phase. Such information is difficult to obtain for a minor uranyl phase that is disseminated in sediment.

We assumed that the uranyl surface site concentration was proportional to the precipitated uranyl concentration, which yielded the following transformation of Eqn. 6:

$$
\frac{\mathrm{dU}(\mathrm{VI})_{\mathrm{aq}}}{\mathrm{dt}}=\mathrm{k}\left[\mathrm{U}(\mathrm{VI})_{\mathrm{solid}}\right]\left[\mathrm{HCO}_{3}^{-}\right]_{\mathrm{tot}}\left(1-\mathrm{IAP} / \mathrm{K}_{\mathrm{sp}}\right)
$$

where $\left[\mathrm{U}(\mathrm{VI})_{\text {solid }}\right]$ is the precipitated uranyl concentration (M) and $\mathrm{k}$ is an apparent rate parameter with a unit of $(\mathrm{mol} / \mathrm{L}$ 
of $\left.\left[\mathrm{HCO}_{3}{ }^{-}\right]_{\mathrm{tot}}\right)^{-1} \mathrm{~h}^{-1}$. Because both $\mathrm{CO}_{3}{ }^{2-}$ and $\mathrm{HCO}_{3}{ }^{-}$ have a similar effect on solubilizing U(VI) from sediments (Mason et al., 1997), the rate expression 7 used total $\mathrm{HCO}_{3}{ }^{-}$ $\left(\left[\mathrm{HCO}_{3}{ }^{-}\right]_{\text {tot }}\right)$ (i.e., sum of $\mathrm{CO}_{3}{ }^{2-}$ and $\mathrm{HCO}_{3}{ }^{-}$concentrations) as a proxy for $\left\{\mathrm{HCO}_{3}{ }^{-}\right\}$in the following modeling.

Eqn. 7 implies that uranyl dissolution will decrease and cease when the dissolving phases approach equilibrium with the contacting electrolyte. Such behavior was noted in Figure 4 at $\mathrm{pH}=7.3$ and $\mathrm{pH}=7.6$ where $\mathrm{U}(\mathrm{VI})$ dissolution was both slow and limited. The initial U(VI) release was slightly larger than the calculated saturation concentration using log $\mathrm{K}_{\mathrm{sp}}$ values in Table 3 for all samples and thus, there was only a slight increase in aqueous uranyl concentration during the entire dissolution experiment. These apparent steady state concentrations were better described using new solubility constants $\left(\log \mathrm{K}_{\mathrm{sp}}\right)$ for Hanford sediment: i.e., 6.08 for Na-boltwoodite or 12.2 for uranophane (Section 4.1). These new $\log \mathrm{K}_{\mathrm{sp}}$ values were used in subsequent kinetic modeling.

\subsection{Modeling of Coupled Mass Transfer and Kinetic Dissolution}

Uranyl mass transfer from intraparticle regions has been modeled previously using diffusion processes to describe the slow release of U(VI) from monazite ore (Olander and Eyal, 1990). The authors utilized a diffusion model with time-decreasing diffusivity to describe the dramatic decrease in the experimentally observed leaching rate with time. The solid phase in the diffusion model was assumed to be homogeneous. The fitted diffusivity was, however, many orders of magnitude higher than the diffusivity in the crystal lattice, suggesting that uranyl transport occurred through fractures in the rock matrix. It was suggested that the time-variable diffusivity indicated different degrees of fracture connectivity within the U-containing particles. A mass transfer limitation was also observed in uranyl leaching from soils (Braithwaite et al., 1997), where a decreasing release rate was modeled by a piecewise first-order kinetic expression with a first-order rate constant that decreased with time.

Our experimental observations of time variable U(VI) release rates combined with the microscopic observations of uranyl microprecipitates within intragrain fractures (Fig. 2) led us to construct a fracture-matrix diffusion model to describe $\mathrm{U}(\mathrm{VI})$ release from the intraparticle domain. The model included: i) diffusion within fractures that were well connected to the interparticle aqueous phase, and ii) diffusion in secondary, more removed fractures (henceforth referred to as matrix). The matrix diffusion model is conceptually representative of diffusion in an assemblage of smaller fractures and cleavages with poor intragrain connectivity, high tortuosity, or steric limitation. Uranyl microprecipitates in both fractures and the matrix were allowed to dissolve. The dissolved uranyl from the fractures was allowed to directly diffuse to the bulk solution, while that from the matrix was released to the fracture before diffusing to the bulk solution. The microscopic transport model was described as follows.
Fracture diffusion-dissolution for the aqueous phase

$$
\frac{\partial C_{f}}{\partial t}=\left(\frac{D_{f}}{L_{f}^{2}}\right) \frac{\partial^{2} C_{f}}{\partial l^{2}}+r_{f}-f_{2} k_{m}\left(C_{f}-C_{m}\right)
$$

Matrix diffusion-dissolution for the aqueous phase:

$$
\frac{\partial C_{m}}{\partial t}=k_{m}\left(C_{f}-C_{m}\right)+r_{m}
$$

Dissolution in the fractures of the solid phase:

$$
\frac{\partial m_{f}}{\partial_{t}}=-r_{f}
$$

Dissolution in the matrix of the solid phase:

$$
\frac{\partial m_{m}}{\partial t}=-r_{m}
$$

Mass balance in the sediment suspension:

$$
\frac{d C_{s o l}}{\partial t}=-f_{1} \frac{d \overline{C_{f}}}{\partial t}-f_{1} \frac{d \overline{m_{f}}}{\partial t}-f_{1} f_{2} \frac{d \overline{C_{m}}}{\partial t}-f_{1} f_{2} \frac{d \overline{m_{m}}}{\partial t}
$$

where $C_{f}$ and $C_{m}$ are the aqueous concentrations in fracture and matrix, respectively; $m_{f}$ and $m_{m}$ are the precipitated concentrations normalized to the local pore volume in fracture and matrix, respectively; $f_{1}$ is the ratio of fracture pore volume vs. bulk aqueous solution volume; $f_{2}$ is the matrix and fracture pore volume ratio (matrix pore volume/fracture pore volume); and $r_{f}$ and $r_{m}$ are the kinetic rates of uranyl dissolution in the fracture and matrix, respectively, with the rate expression described by Eqn. 7; and $l$ is the dimensionless length from fracture opening to the interior. A bar over concentration (e.g., $\bar{C}_{f}$ ) indicated a domain-averaged value. $D_{f} / L_{f}^{2}$ is the fracture diffusivity normalized to the half fracture length when both ends of the fracture are open to bulk solution, or the full fracture length when only one end is exposed. Parameter $k_{m}$ is the mass transfer coefficient between the fracture and matrix.

Diffusion in the matrix was described using a first-order mass transfer model (Eqn. 9) to avoid the complication of matrix geometry. The length-normalized fracture diffusivity $\left(D_{f} / L_{f}^{2}\right)$ was used as a single parameter in the model calculation because of the difficulty in separating diffusivity and fracture length. A similar approach was used to describe the influence of intraparticle diffusion on cesium desorption from Hanford sediments (Liu et al., 2003).

Eqns. 8 to 12 describe a microscopic U(VI) transport model from two intraparticle domains. The model does not account for the variable diffusivities of different U(VI) species. The diffusivity of charged aqueous species will be coupled with one another through the electrostatic diffusion potential. A more complete diffusion-reaction model could be assembled by coupling speciation reactions with the diffusivities of different charged species. However, this would involve more parameters at the microscopic level that would be difficult to determine independently. The diffusion model (Eqns. 8 to 12), coupled with U(VI) dissolution kinetics (Eqn. 7 using Na-boltwoodite to limit solubility with $\log \mathrm{K}_{\mathrm{sp}}=6.08$ ), was used to evaluate 
Table 5. Dissolution/diffusion parameters for U(VI) release from Hanford sediments.

\begin{tabular}{ccccc} 
& $\begin{array}{c}k(\mathrm{~mol} / \mathrm{L} \text { of } \\
\left.\left[\mathrm{HCO}_{3}^{-}\right]_{\mathrm{tot}}\right)^{-1} \mathrm{~h}^{-1}\end{array}$ & $k_{m} \mathrm{~h}^{-1}$ & $D_{f} / \mathrm{L}_{f}^{2} \mathrm{~h}^{-1}$ & $1 / f_{2}$ \\
Sample & 0.066 & 0.0035 & 6.8 & 95 \\
\hline I53 & 0.066 & 0.0035 & 0.26 & 50 \\
I61 & 0.066 & 0.0035 & 6.8 & 85 \\
I67 & \multicolumn{2}{c}{} \\
\hline
\end{tabular}

the relative importance of coupled diffusion and dissolution kinetics on uranyl release. The effects of diffusion of other species and uranyl sorption were incorporated into the apparent diffusivity and mass transfer coefficients (i.e., $D_{f}$ and $k_{m}$ ) of $\mathrm{U}(\mathrm{VI})$.

The boundary condition at the particle surface was chosen to be the bulk solution concentration as a function of time. The measured concentration at the first sampling point $(0.08 \mathrm{~d})$ was used as the initial bulk solution concentration. A no flux condition was imposed at the interior ends of the fractures or at the middle of a two-end open fracture. The pore-water uranium concentration (Table 2) was used as the initial aqueous concentration within the fracture and matrix. The total uranium concentration (Table 1) was used as the initial solid uranium concentration after deducting the amount of uranium in the pore water. The solid phase uranium concentration was assumed to be homogeneous. Given this assumption, the parameter $f_{2}$ represented the initial mass ratio of $\mathrm{U}(\mathrm{VI})$ in the matrix and fracture $\left[\mathrm{U}(\mathrm{VI})_{\mathrm{m}} / \mathrm{U}(\mathrm{VI})_{\mathrm{f}}\right]$. The parameter $f_{l}$ was calculated to be $7.5 \times 10^{-5}$ based on the experimental sediment-water ratio, an assumed $2.67 \mathrm{~g} / \mathrm{cm}^{3}$ solid density, and an intraparticle fracture volume of $0.1 \%$ estimated from SEM analysis of uranium-containing particles (McKinley et al., 2002). The initial bulk solution concentration was assumed to be zero for simulation of $\mathrm{U}(\mathrm{VI})$ dissolution in $\left(\mathrm{NH}_{4}\right)_{2} \mathrm{CO}_{3}$ electrolyte. The measured aqueous carbonate and silicate concentrations and $\mathrm{pH}$ (Appendix 1, Tables A1 to A5) were used in the dissolution simulation.

The coupled diffusion and dissolution model (Eqns. 7 to 9) was solved by a Crank-Nicholson finite difference scheme for concentrations in fracture and matrix $\left(C_{f}\right.$ and $\left.C_{m}\right)$, which were then used to update precipitated concentrations in fracture and matrix $\left(m_{f}\right.$ and $\left.m_{m}\right)$, and bulk concentration $\left(C_{s o l}\right)$ from Eqns. 10 to 12 . The updated $m_{f}, m_{m}$, and $C_{\text {sol }}$ were used to calculate $C_{f}$ and $C_{m}$ again from Eqns. 7 to 9 . This process was iterated until convergence at every time step. A relative error of $1 \times$ $10^{-6}$ was used to control global convergence of $C_{f}, C_{m}$, and $C_{s o l}$ for iteration. In the evaluation of kinetic dissolution rates $\left(\mathrm{r}_{\mathrm{f}}\right.$ and $\mathrm{r}_{\mathrm{m}}$ ) in Eqns. 8 to 11 , the updated local $C_{f}$ and $C_{m}$ were used to calculate term IAP/K $/ \mathrm{K}_{\mathrm{sp}}$ in Eqn. 7. The Davies equation was used to calculate the activity coefficients for IAP evaluation. The model was used to simultaneously fit all experimental data in Figure 4 and Figure 5 by adjusting 4 parameters: the kinetic rate constant $(k)$, the mass transfer coefficient $\left(k_{m}\right)$, the normalized fracture diffusivity $\left(D_{f} / L_{f}^{2}\right)$, and the uranyl mass ratio between fracture and matrix $\left(f_{2}\right)$. After an optimal set of these parameters were estimated, we then finely tuned the parameters $D_{f} / L_{f}^{2}$ and $f_{2}$ to best match the experimental results for each sample while the parameters $k$ and $k_{m}$ were fixed at the same value for all samples. The fitted parameters are listed in Table 5.

The estimated fracture diffusivity value $\left(D_{f} / L_{f}^{2}=6.8 \mathrm{~h}^{-1}\right)$ for sample I53 and I67 was on the order of molecular diffusivity of the uranyl ion in pure water $\left(4.26 \times 10^{-10} \mathrm{~m}^{2} / \mathrm{s}\right)$ (Lide, 2003) when corrected by a tortuosity factor of 2.5 assuming the characteristic fracture length $\left(L_{f}\right)$ of $0.3 \mathrm{~mm}$. Sample I61 was different, however, and a much smaller diffusivity (Table 5) was needed to simultaneously fit the results in Figures 4 and 5. The estimated mass transfer coefficient $\left(k_{m}\right)$ between the matrix and fracture was small. Using an approximate relationship of $k_{m}=D_{m} / L_{m}^{2}$ (Cussler, 1995) where $D_{m}$ is the matrix diffusivity and $L_{m}$ is the average diffusion distance in the matrix, respectively, the effective diffusivity in the matrix was estimated to be $D_{m}<\mathrm{k}_{\mathrm{m}} \mathrm{L}_{\mathrm{f}}^{2}=8.75 \times 10^{-14} \mathrm{~m}^{2} / \mathrm{s}$, which was over three orders of magnitude less than that in the fracture.

The dissolution rate constant $(k)$ (Eqn. 7) of 0.066 (mol/ $\mathrm{L})^{-1} \mathrm{~h}^{-1}$ (Table 5) was in the lower range of those reported in the literature for uranyl mineral dissolution (Table 6). Literature rate constants are typically normalized to surface area. We normalized the literature rate constants to total uranium concentration in Table 6 for comparative purposes because of the difficulty in measuring the surface area of intraparticle uranyl silicates in this study. Our dissolution rate constant [0.066 $(\mathrm{mol} / \mathrm{L})^{-1} \mathrm{~h}^{-1}$ ] was about an order of magnitude lower than those of pure phase uranophane, soddyite, and $\mathrm{UO}_{3} \cdot \mathrm{H}_{2} \mathrm{O}$ (Table 6), but larger than that of $\mathrm{U}_{3} \mathrm{O}_{8}$.

Between 85 to $95 \%$ of the U(VI) in samples I53 and I67 was computed to exist in fractures with good connectivity to the

Table 6. Rate constants for uranyl mineral dissolution.

\begin{tabular}{|c|c|c|c|c|c|}
\hline Mineral & $\begin{array}{l}\text { Surface area } \\
\mathrm{m}^{2} / \mathrm{g}\end{array}$ & $\begin{array}{l}\text { Rate }(\mathrm{mg} \\
\left.\mathrm{U} / \mathrm{m}^{2}\right) / \mathrm{d}\end{array}$ & $\begin{array}{c}{\left[\mathrm{HCO}_{3}{ }^{-}\right]_{\text {tot }}} \\
\mathrm{mol} / \mathrm{L}\end{array}$ & $\begin{array}{l}\text { Rate constant }{ }^{\mathrm{a}}(\mathrm{mol} / \mathrm{L} \text { of } \\
\left.\qquad\left[\mathrm{HCO}_{3}{ }^{-}\right]_{\mathrm{tot}}\right)^{-1} \mathrm{~h}^{-1}\end{array}$ & Source \\
\hline Uranophane (flow-through) & 35.4 & $0.06-2.0$ & $0.001-0.02$ & $0.09-0.72$ & 1 \\
\hline Uranophane (batch) & 35.4 & $0.82-16.3$ & $0.001-0.02$ & $0.25-5.14$ & 1 \\
\hline Soddyite & 25.4 & $2.5-25.3$ & $0.008-0.02$ & $0.47-2.52$ & 2 \\
\hline $\mathrm{U}_{3} \mathrm{O}_{8}$ & 0.18 & $0.8-21$ & $0.0002-0.02$ & $0.004-0.06$ & 3 \\
\hline $\mathrm{UO}_{3} \cdot \mathrm{H}_{2} \mathrm{O}$ & 0.32 & $100-700$ & $0.0002-0.02$ & $0.17-1.02$ & 3 \\
\hline Na-Boltwoodite or uranophane & & & $0.001-0.5$ & 0.066 & 4 \\
\hline
\end{tabular}

a The rate constant was normalized to total carbonate and total uranium concentrations at which the rate was determined (i.e., rate constant $=$ rate $\times \mathrm{A} \times \mathrm{w} /\left(\left[\mathrm{HCO}_{3}{ }^{-}\right]_{\text {tot }} \times 24000\right)$, where $\mathrm{A}$ is the surface area of a uranium mineral, $\mathrm{w}=\mathrm{FW} /(v \times 238.03), \mathrm{FW}$ is the formula weight and $v$ is the stoichiometric coefficient of uranium in the formula for a uranyl mineral, respectively. 1. Perez et al. (2000); 2. Perez et al. (1997); 3. Steward and Mones (1997); 4. This study. 
solution phase ( $1 / f_{2}$ in Table 5). This fraction decreased to $50 \%$ for I61. Dissolution in, and diffusion from these fractures controlled the dynamic picture of the kinetic profile from 0 to approximately $100 \mathrm{~h}$ (Fig. 6). The calculated time variable $\mathrm{U}(\mathrm{VI})$ concentrations in the fracture and matrix in Figure 6 were normalized to bulk solution volume [i.e., $\left(C_{f}+m_{f}\right) / f_{1},\left(C_{m}\right.$ $\left.\left.+m_{m}\right) /\left(f_{l f 2}\right)\right]$. The fracture associated uranyl silicate was insufficient to saturate the aqueous phase with Na-boltwoodite or uranophane at $\mathrm{pH} \approx 9$ (Fig. 3). The remaining fraction of uranium was in the matrix and its transport to the aqueous phase occurred more slowly (Fig. 6). Using the model param-
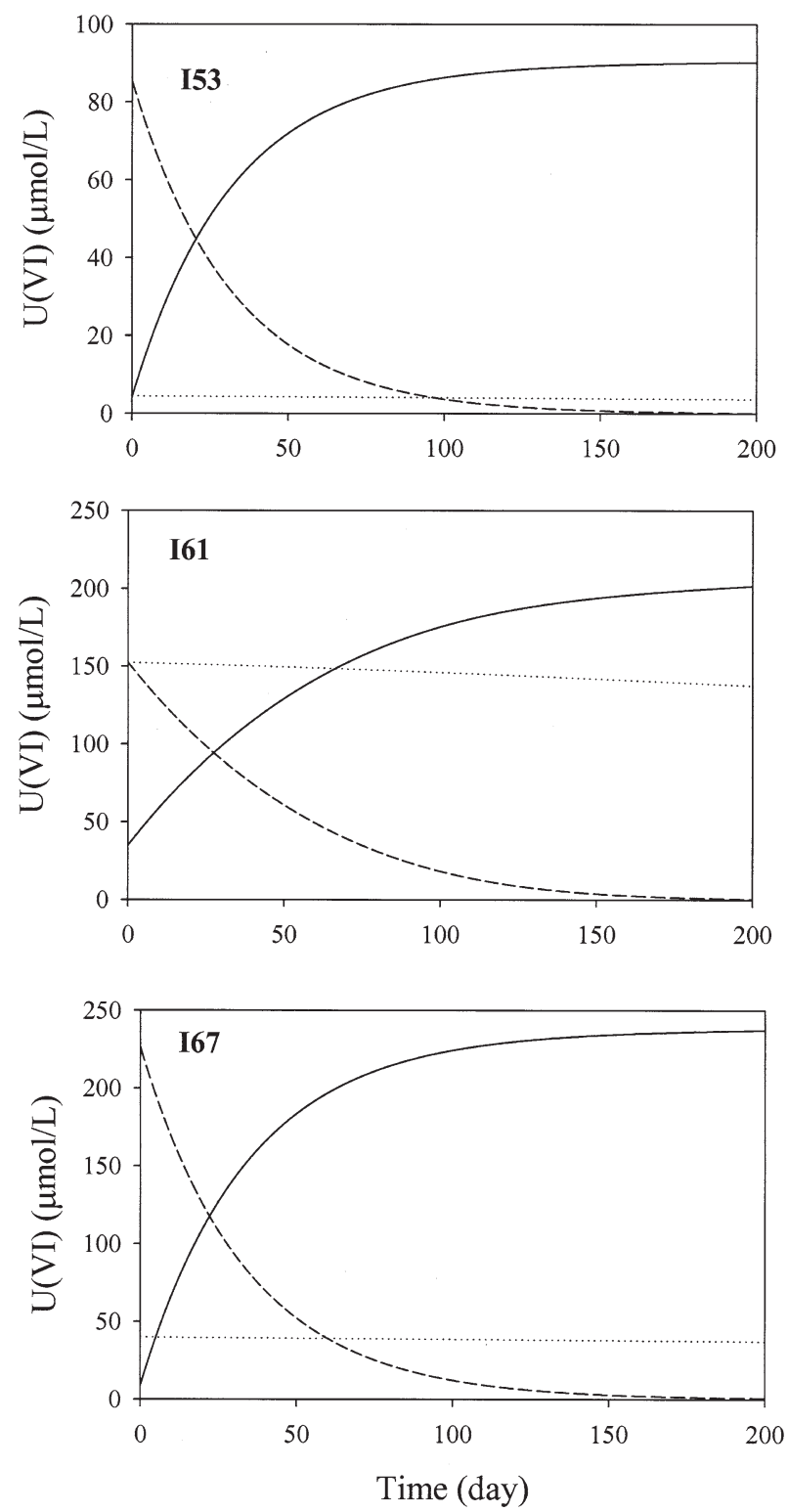

Fig. 6. Calculated U(VI) mass distribution in bulk solution (solid line), fractures (short dashed line), and the matrix domains (dotted line) corresponding to the dissolution experiment in $\mathrm{Na}-\mathrm{NO}_{3}-\mathrm{HCO}_{3}$ electrolyte at $\mathrm{pH} 9.25$ (Fig. 4). The time-variable U(VI) concentrations in the fracture and matrix domains were reported as normalized to bulk solution volume [i.e., $\left(C_{f+m f}\right) / f_{l}$ for fracture, and $\left(C_{m}+m_{m}\right) /\left(f_{l f 2}\right)$ for matrix]. eters in Table 5, we calculated that over 95 and $90 \%$ of total uranium in samples I53 and I67, respectively, was not subject to mass transfer limitation. The U(VI) release rate from these sediments was controlled by dissolution kinetics only. In contrast, only $40 \%$ of the precipitated U(VI) in sample I61 was computed to dissolve without mass transfer limitation, because of the lower apparent diffusivity of the fracture region. X-ray micrographs of samples I61 and I67 after $200 \mathrm{~d}$ of dissolution in electrolytes with $\mathrm{pH} 9.25$ showed a contrast in the abundance of intragrain precipitates (Fig. 7).

\subsection{Implications for the Uranium Distribution Coefficient $\left(k_{d}\right)$}

The distribution coefficient $\left(K_{d}\right)$ is often used in performance assessment calculations to describe retardation extent through the retardation factor. Some adsorption processes exhibit a linear isotherm at low concentration, and for these, a single value of $K_{d}$ can be used to describe the solid-liquid partitioning process as it controls retardation. Here, the $K_{d}$ for uranium in the dissolution experiments was found to vary greatly with $\mathrm{pH}$, bicarbonate/carbonate concentration, and contact time for all three sediments (Fig. 8). Values of $K_{d}$ ranged from high values (e.g., $>400 \mathrm{~mL} / \mathrm{g}$ ) where uranium would be virtually immobile, to lower values (e.g., $3.2 \mathrm{~mL} / \mathrm{g}$ ) where retarded mobility would occur. The $K_{d}$ could also vary significantly with solid: solution ratio if this variable had been changed in the experiments, because the total amount of uranium that will dissolve from a solid phase is dependent on the volume of water in contact with it. These large variations in $K_{d}$ result from the fact that uranium solid-liquid distribution is controlled by a kinetic release process that was collectively controlled by solubility saturation degree, dissolution kinetics, and mass transfer limitation. While our kinetic and solubility experiments were performed at $200 \mathrm{~g} / \mathrm{L}$, much higher ratios $\left(>2.7 \times 10^{4} \mathrm{~g} / \mathrm{L}\right)$ exist in the Hanford vadose zone and larger in-situ $\mathrm{K}_{\mathrm{d}}$ values would consequently result.

The large noted variation in $K_{d}$ with $\mathrm{pH}$ change in BX-102 sediment (Fig. 8) indicates that a single value of $K_{d}$ will not be an accurate predictor of uranium retardation in the BX-102 uranium plume. The measured $\mathrm{pH}$ values in the $\mathrm{BX}-102$ core samples varied by over one unit at the end of the dissolution experiment (Appendix A, Tables A3 and A4) and measurements from proximate samples as received exhibited significantly different $\mathrm{pH}$ values (Serne et al., 2002). Moreover, the variations in $K_{d}$ noted between the three sediments showed that $K_{d}$ was a complex and dynamic function of precipitate distribution on and within sediment grains, and dissolution kinetics and mass transfer rates from intraparticle regions and grain coatings. These complex dependencies argue strongly against the use of $K_{d}$ to forecast the future redistribution of the BX-102 plume unless a bounding calculation is desired. More sophisticated geochemical simulators that explicitly deal with the solubility, dissolution kinetics, and mass transfer rates are needed.

\section{CONCLUSIONS}

We were fortunate to obtain three low moisture content subsurface sediments from the Hanford site with micron- 

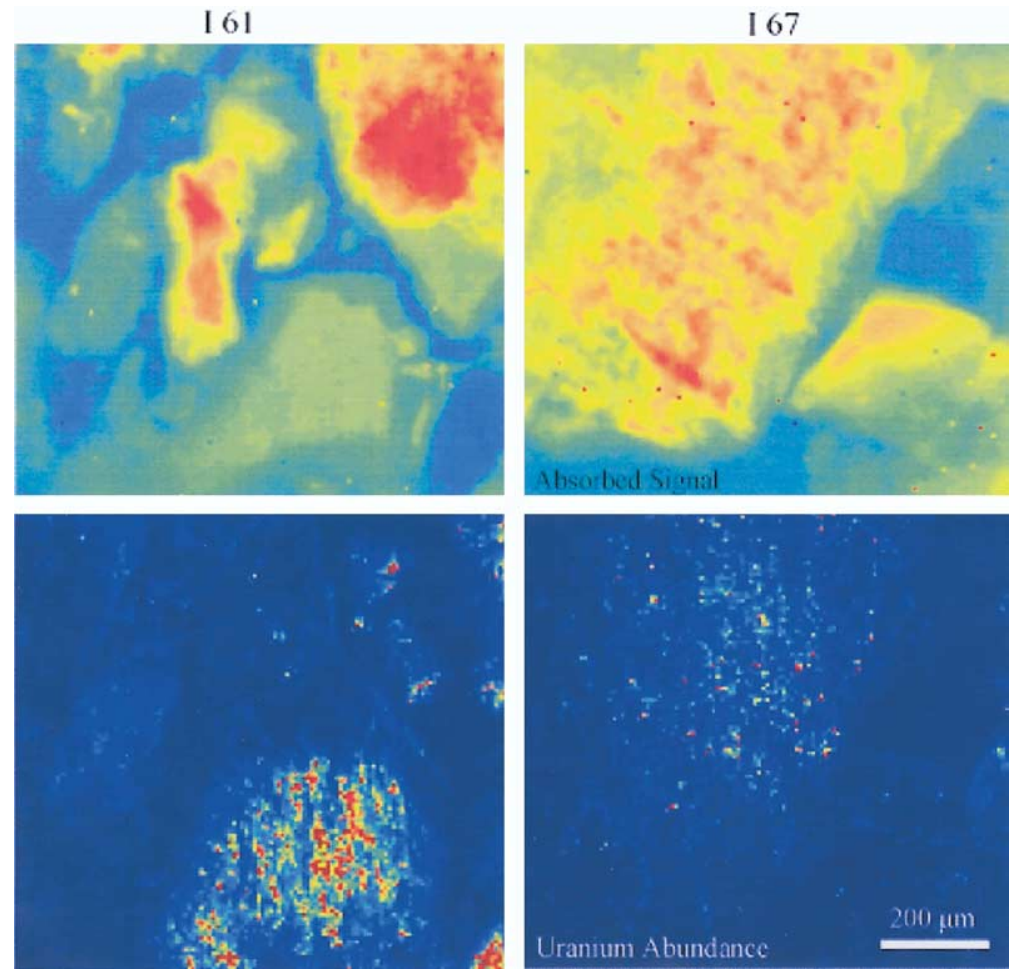

Fig. 7. False-color X-ray maps for the absorbance of X-ray beam flux (indicating the approximate sample grain geometry, top two panels) and for uranium abundance (red indicates the highest uranium abundance) in samples I61 and I67 (bottom two panels). The samples were measured after $200 \mathrm{~d}$ of uranyl dissolution.

sized intragranular precipitates of uranyl silicates. The mineralogic identity of the uranyl silicate has not been definitively determined but it exhibits spectral and solubility characteristics similar to Na-boltwoodite or uranophane. The sediment uranyl silicate dissolved slowly in electrolytes representative of the calcareous geochemical environments from which the sediments were obtained. Steady-state concentrations were not achieved at $\mathrm{pH}>8.2$ even after $200 \mathrm{~d}$ of equilibration. A common pseudo-first-order rate constant could describe uranyl silicate dissolution kinetics in the three sediments over a range in $\mathrm{pH}$, electrolyte composition, and bicarbonate/carbonate concentration. In spite of the intragrain residence of much of the precipitated $U$, dissolution kinetics, rather than intragrain mass transfer, appeared to regulate the slow release of $\mathrm{U}(\mathrm{VI})$ to the aqueous phase for two of the samples (I53, I67). Mass transfer was a major limitation on U(VI) release from one of the samples (I61). Physicochemical explanations for these differences were not readily apparent, but could result from minor lithologic variations or unknown geochemical or hydrologic aspects of the waste emplacement event which, itself, is not well understood (see McKinley et al., 2002).

A model linking dissolution kinetics and intragrain mass transfer was used to describe the time variant release of U(VI) from the sediments in different electrolytes. The model assumed a homogeneous intragrain distribution of U(VI) and the presence of two interconnected domains with different diffusivities that were termed fracture and matrix. The volume fractions of the two domains were obtained by data fitting. Although we conceptually described the matrix domain as one that was less accessible due to tortuosity and/or fracture fineness, this domain was not explicitly identified or characterized by microscopy. However, the important conclusion was that a physical construct containing two regions of differing diffusivity was required to model the data regardless of their physical conceptualization. The simplest explanation for our data is that the uranyl silicates were rapidly dissolved from grain surfaces and cavities, while the dissolution of intragrain precipitates was limited by distance from the grain surface and the associated longer diffusion time.

The studied sediments were taken from a vadose zone $\mathrm{U}(\mathrm{VI})$ plume that contains over $7000 \mathrm{~kg}$ of $\mathrm{U}(\mathrm{VI})$. The potential of this site to impact groundwater, and four or five more like it in different tank farms, is a major environmental concern at Hanford. The monitoring of groundwater some $30 \mathrm{~m}$ below the plume suggests the slow and incomplete release of sediment-bound $\mathrm{U}(\mathrm{VI})$ from the plume region. Groundwater concentrations are generally far below those that would result if adsorption (that typically yields $K_{d}$ values in the range of 0.25 to $5 \mathrm{~mL} / \mathrm{g}$ ) was the primary retardation process in the plume. Our laboratory dissolution experiments, however, were consistent with the field observation and showed that the precipitated, intragrain U(VI) was released slowly to the aqueous phase. Reactive transport calculations coupling our measured dissolution rates for the uranyl silicates and intragrain diffusivities for the vadose zone lithic fragments, and appropriate geologic and hydrologic information for the vadose zone at this location are required to estimate uranium release rates from vadose zone to groundwater under various recharge scenarios. 

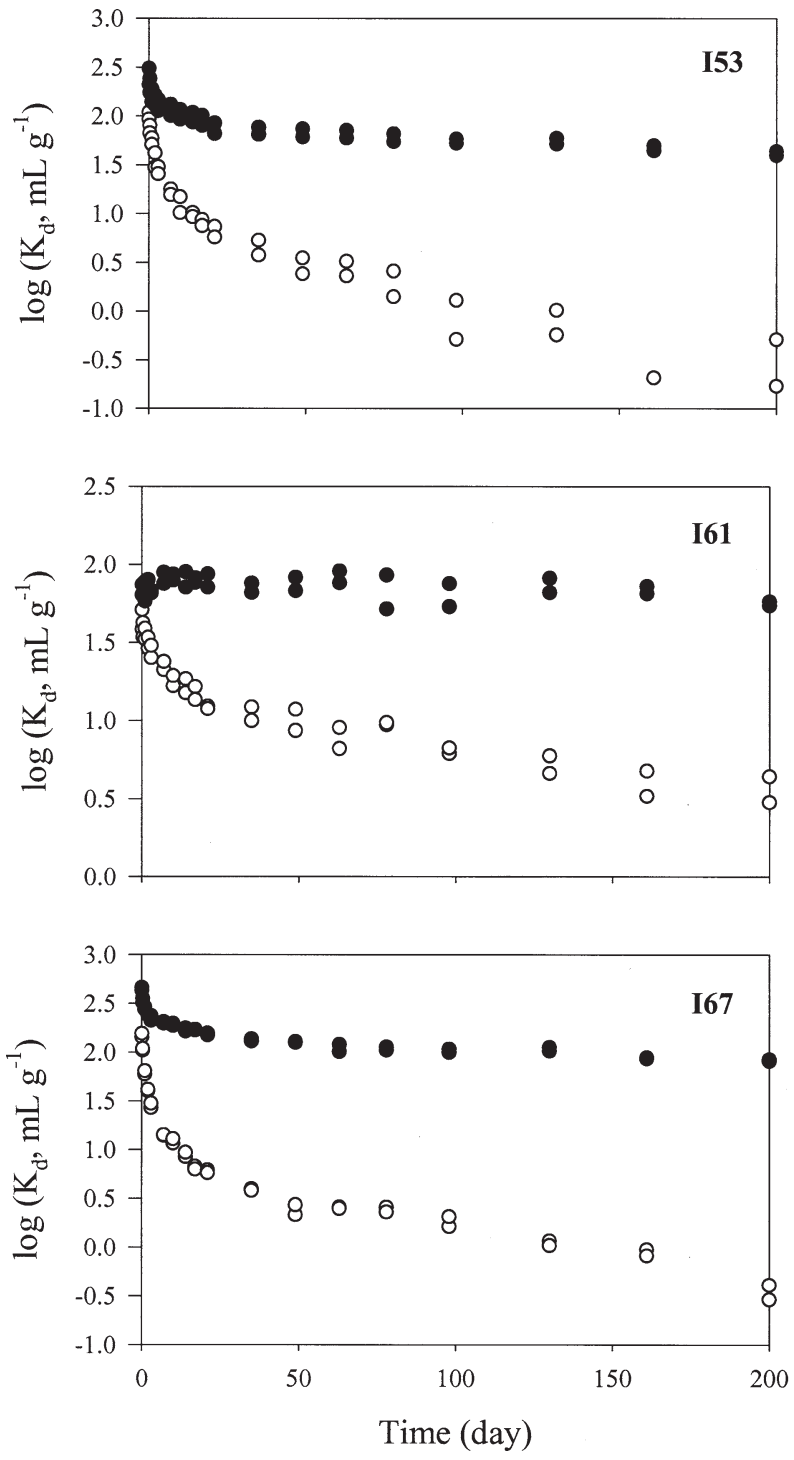

Fig. 8. Distribution coefficients $\left(K_{d}\right)$ for uranium in kinetic dissolution experiments in $\mathrm{Na}-\mathrm{NO}_{3}-\mathrm{HCO}_{3}$ electrolytes at $\mathrm{pH}$ of 7.27 (solid circle) and 9.25 (open circle) corresponding to experimental results in Figure 4 and Appendix 1, Table A3.

Acknowledgments-This research was supported by the U.S. Department of Energy (DOE) through the Environmental Management Sciences Program (EMSP) and the Hanford Remediation and Closure Science Project and the Hanford Vadose Zone Characterization Project managed by $\mathrm{CH} 2 \mathrm{M}$ Hill providing the $\mathrm{U}(\mathrm{VI})$ contaminated sediments. Pacific Northwest National Laboratory (PNNL) is operated for the Department of Energy by Battelle. We thank Associate Editor Dr. Kathryn L. Nagy and three reviewers for their valuable comments and suggestions on the manuscript.

Associate editor: K. Nagy

\section{REFERENCES}

Aagaard P. and Helgeson H. C. (1982) Thermodynamic and kinetic constraints on reaction rates among minerals and aqueous solutions, 1. Theoretical considerations. Am. J. Sci. 282, 237-285.
Allison J. D., Brown D. S., and Novo-Gradac K. J. (1998) MINTEQA2//PRODEFA2, a geochemical assessment model for environmental systems (version 4). Environmental Research Laboratory, U.S. EPA.

ASTM. (1988) Standard Test Method for Total and Organic Carbon in Water by High Temperature Oxidation and by Coulometric Detection. American Society for Testing and Materials.

Bargar J. R., Reimeyer R., and Davis J. A. (1999) Spectroscopic confirmation of uranium(VI)-carbonato adsorption complexes on hematite. Environ. Sci. Technol. 33, 2481-2484.

Bargar J. R., Reimeyer R., Lenhart J. J., and Davis J. A. (2000) Characterization of U(VI)-carbonato ternary complexes on hematite: EXAFS and electrophoretic mobility measurements. Geochim. Cosmochim. Acta 64, 2737-2749.

Braithwaite A., Livens F. R., Richardson S., and Howe M. T. (1997) Kinetically controlled release of uranium from soils. Eur. J. Soil Sci. 48, 661-673.

Catalano J. G., Heald S. M., Zachara J. M., and Brown G. E. J. (2004) Spectroscopic and diffraction study of uranium speciation in contaminated vadose zone sediments from the Hanford site, Washington. Environ. Sci. Tech., 38, 2822-2828.

Chen F., Ewing R. C., and Clark S. B. (1999) The Gibbs free energies and enthalpies of formation of $\mathrm{U}^{6+}$ phases: An empirical method of prediction. Am. Mineral. 84, 650-664.

Cussler E. L. (1995) Diffusion: Mass Transfer in Fluid Systems. Cambridge University Press.

Davis J. A., Payne T. E., and Waite T. D. (2002) Simulating the pH and $\mathrm{pCO}_{2}$ dependence of uranium(VI) adsorption by a weathered schist with surface complexation models. In Geochemistry of Soil Radionuclides,pp. 61-86. Special Publication 59. SSSA.

De Pablo J., Casas I., Gimenez J., Molera M., Rovira M., Duro L., and Bruno J. (1999) The oxidative dissolution mechanism of uranium dioxide. I. The effect of temperature in hydrogen carbonate medium. Geochim. Cosmochim. Acta 63, 3097-3103.

Duff M. C. and Amrhein C. (1996) Uranium(VI) adsorption on goethite and soil in carbonate solutions. Soil Sci. Soc. Am. J. 60, 1393-1400.

Duff M. C., Mason C. F. V., and Hunter D. B. (1998) Comparison of acid and base leach for the removal of uranium from contaminated soil and catch box media. Can. J. Soil Sci. 78, 675-683.

Duff M. C., Morris D. E., Hunter D. B., and Bertsch P. M. (2000) Spectroscopic characterization of uranium in evaporation basin sediments. Geochim. Cosmochim. Acta 64, 1535-1550.

Duff M. C., Coughlin J. U., and Hunter D. B. (2002) Uranium coprecipitation with iron oxide minerals. Geochim. Cosmochim. Acta 66, 3533-3547.

Fuhrmann M., Zhou H., Neiheisel J., Schoonen M. A. A., and Dyer R. (1997) Sorption/desorption of radioactive contaminants by sediment from the Kara Sea. Sci. Total Environ. 202, 5-24.

Giammar D. E. and Hering J. G. (2001) Time scales for sorptiondesorption and surface precipitation of uranyl on goethite. Environ. Sci. Technol. 35, 3332-3337.

Grenthe I., Fuger J., Konings R. J. M., Lemire R. J., Muller A. B., Nguyen-Trung C., and Wanner H. (1992) Chemical Thermodynamics.Vol. 1,Chemical Thermodynamics of Uranium. OECD-NEA, Elsevier.

Guillaumount R., Fanghänet T., Neck V., Fuger J., Palmer D. A., Grenthe I., and Rand M. H. (2003)Update on the Chemical Thermodynamics of Uranium, Neptunium, Pluytonium, Americium and Technetium. Elsevier.

Heald S. M., Brewe D. L., Stern E. A., Kim K. H., Brown F. C., Jiang D. T., Crozier E. D., and Gordon R. A. (1999) XAFS and microXAFS at the PNC-CAT beamlines. J. Synchrotron Radiat. 6, 347349.

Hiskey J. B. (1979) Kinetics of uranium dioxide dissolution in ammonium carbonate. Inst. Min. Metal. Trans. 88, c145.-c152.

Hiskey J. B. (1980) Hydrogen peroxide leaching of uranium in carbonate solutions. Inst. Min. Metal. Trans. 89, c145.-c152.

Hsi C.-K. and Langmuir D. (1985) Adsorption of uranyl onto ferric oxyhydroxides: Application of the surface complexation site-biding model. Geochim. Cosmochim. Acta 49, 1931-1941.

Hudson E. A., Terminello L. J., Viani B. E., Denecke M., Reich T., Allen P. G., Bucher J. J., Shuh D. K., and Edelstein N. M. (1999) 
The structure of $\mathrm{U}^{6+}$ sorption complexes on vermiculite and hydrobiotite. Clays Clay Miner. 47, 439-457.

Jones T. E., Simpson B. C., Wood M. I., and Corbin R. A. (2001) Preliminary inventory estimates for single-shell tank leaks in B, BX, and BY tank farms. CH2MHill Hanford Group, Richland, WA.

Kalmykov S. N. and Choppin G. R. (2000) Mixed $\mathrm{Ca}^{2+} / \mathrm{UO}_{2}{ }^{2+} / \mathrm{CO}_{3}{ }^{2-}$ complex formation at different ionic strengths. Radiochim. Acta $\mathbf{8 8}$, 603-606.

Langmuir D. (1978) Uranium solution-mineral equilibria at low temperatures with applications to sedimentary ore deposits. Geochim. Cosmochim. Acta 42, 547-569.

Lenhart J. J. and Honeyman B. D. (1999) Uranium(VI) sorption to hematite in the presence of humic acid. Geochim. Cosmochim. Acta 63, 2891-2901.

Lide D. R. (2003) Handbook of Chemistry and Physics. 84th ed CRC Press.

Liu C., Zachara J. M., Smith S. C., McKinley J. P., and Ainsworth C. C. (2003) Desorption kinetics of radiocesium from the subsurface sediments at Hanford site, USA. Geochim. Cosmochim. Acta 67, 2893-2912.

Mason C. F., Turney W. R., Thomson B. M., Lu N., Longmire P. A., and Chisholm-Brause C. J. (1997) Carbonate leaching of uranium from contaminated soils. Environ. Sci. Technol. 31, 2707-2711.

McKinley J. P., Zachara J. M., Smith S. C., and Turner G. (1995) The influence of uranyl hydrolysis and multiple site-binding reactions on adsorption of $\mathrm{U}(\mathrm{VI})$ to montmorillonite. Clays Clay Miner. 43, 586-598.

McKinley J. P., Heald S. M., Zachara J. M., and Resch C. T. (2002) The identification of uranium-bearing phases by X-ray microprobe, electron microprobe, and scanning electron microscopy. In Field Investigation Report for Waste Management Area B-BX-BY. pp D122-D139. River Protection Project (RPP). RPP-10098, Prepared for the Office of River Protection by CH2M Hill Hanford Group, Richland, Washington.

Moll H., Geipel G., Matz W., Bernhard G., and Nitsche H. (1996) Solubility and speciation of $\left(\mathrm{UO}_{2}\right)_{2} \mathrm{SiO}_{4}-\mathrm{H}_{2} \mathrm{O}$. Radiochim. Acta 74, 3-7.

Nguyen S. N., Silva R. J., Weed H. C., and Andrews J. E. J. (1992) Standard Gibbs free energies of formation at the temperature $303.15 \mathrm{~K}$ of four uranyl silicates: Soddyite, uranophane, sodium boltwoodite and sodium weeksite. J. Chem. Thermodyn. 24, 359376.

Nicol M. J. and Needes C. R. S. (1977) The anodic dissolution of uranium dioxide-II. in carbonate solution. Electrochim. Acta 22, $1381-1384$.

Ohnuki T., Isobe H., Yanase N., Nagano T., Sakamoto T., and Sekine K. (1997) Change in sorption-characteristics of uranium during crystallization of amorphous iron minerals. J. Nucl. Sci. Technol. 34, 1153-1158.

Olander D. R. and Eyal Y. (1990) Leaching of uranium and thorium from monazite: II. Elemental leaching. Geochim. Cosmochim. Acta 54, 1879-1887.

Payne T. E., Davis J. A., and Waite T. D. (1996) Uranium adsorption on ferrihydrite-effects of phosphate and humic acid. Radiochim. Acta 74, 239-243.

Perez I., Casas I., Torrero M. E., Duro L., and Bruno J. (1997) Dissolution studies of soddyite as a long-term analogue of the oxidative alteration of the spent nuclear fuel matrix. Mat. Res. Soc. Symp. Proc. 465, 565-572.
Perez I., Casas I., Martin M., and Bruno J. (2000) The thermodynamics and kinetics oaf uranophane dissolution in bicarbonate test solutions. Geochim. Cosmochim. Acta 64, 603-608.

Riley R. G. and Zachara J. M. (1992) Chemical contaminants on DOE lands and election of contaminant mixtures for subsurface science research. U.S. Department of Energy, Office of Energy Research, Washington, DC.

Serne R. J., Bjornstad B. N., Gee G. W., Schaef H. T., Lanigan D. C., Lindenmeirer C. W., Orr R. D., LeGore V. L., Clayton R. E., Lindberg M. J., Kutnyakov I. V., Baum S. R., Geiszler K. N., Valenta M. M., Vickerman T. S., and Royack L. J. (2002) Characterization of Vadose zone sediment: Borehole 299-E33-46 near tank B-110 in the B-BX-BY waste management area. Pacific Northwest National Laboratory, Richland, WA.

Sharma J. N., Bhattacharya K., Swami R. G., Tangri S. K., and Mukherjee T. K. (1996) Studies of the kinetics of $\mathrm{UO}_{2}$ dissolution in carbonate-bicarbonate medium using sodium hypochlorite as oxidant. J. Radioanal. Nucl. Chem. Lett. 214, 223-233.

Shoesmith D. W., Sunder S., Bailey M. G., and Wallace G. J. (1989) The corrosion of nuclear fuel $\left(\mathrm{UO}_{2}\right)$ in oxygenated solution. Corros. Sci. 29, 1115-1128.

Shoesmith D. W., Betteridge J. S., and Hocking W. H. (1996a) The cathodic reduction of oxygen on n-type $\mathrm{UO} 2$ in dilute alkaline aqueous solution. J. Electroanal. Chem. 406, 69-81.

Shoesmith D. W., Sunder S., Bailey M. G., and Miller N. H. (1996b) The corrosion of used nuclear fuel in aqueous perchlorate and carbonate solutions. J. Nucl. Mater. 227, 287-299.

Shoesmith D. W., Sunder S., and Tait J. C. (1998) Validation of an electrochemical model for the oxidative dissolution of used CANDU fuel. J. Nucl. Mater. 257, 89-98.

Sowder A. G., Clark S. B., and Fjeld R. A. (1998) The effect of sample matrix quenching on the measurement of trace uranium concentrations in aqueous solutions using kinetic phosphorimetry. J. Radioanal. Nucl. Ch. 234, 257-260.

Sowder A. G., Clark S. B., and Fjeld R. A. (2001) The impact of mineralogy in the $\mathrm{U}(\mathrm{VI})-\mathrm{Ca}-\mathrm{PO}_{4}$ system on the environmental availability of uranium. J. Radioanal. Nucl. Ch. 248, 517-524.

Steward S. A. and Mones E. T. (1997) Comparison and modeling of aqueous dissolution rates of various uranium oxides. Mat. Res. Soc. Symp. Proc. 465, 557-564.

Sunder S., Shoesmith D. W., Kolar M., and Leneveu D. M. (1997) Calculation of used nuclear fuel dissolution rates under anticipated Canadian waste vault conditions. J. Nucl. Mater. 250, 118-130.

Sylwester E. R., Hudson E. A., and Allen P. G. (2000) The structure of uranium(VI) sorption complexes on silica, alumina, and montmorillonite. Geochim. Cosmochim. Acta 64, 2431-2438.

Turner G. D., Zachara J. M., McKinley J. P., and Smith S. C. (1996) Surface-charge properties and $\mathrm{UO}_{2}{ }^{2+}$ adsorption of a subsurface smectite. Geochim. Cosmochim. Acta 60, 3399-3414.

Waite T. D., Davis J. A., Fenton B. R., and Payne T. E. (2000) Approaches to modeling uranium(VI) adsorption on natural mineral assemblages. Radiochim. Acta 88, 687-693.

Waite T. D., Davis J. A., Payne T. E., Waychunas G. A., and Xu N. (1994) Uranium(VI) adsorption to ferrihydrite: Application of a surface complexation model. Geochim. Cosmochim. Acta 58, $5465-5478$.

Wang Z., Zachara J. M., Gassman P. L., Liu C., Qafoku O., and Catalano J. G. (2004) Fluorescence spectroscopy of U(VI)-silicate and U(VI)-contaminated Hanford sediment. Geochim. Cosmochim. Acta, in press. 
APPENDIX A

\section{Selected Solutes Measured in Uranium Dissolution Experiments}

Tables A1 and A2 show analyses of electrolyte solutions in the uranium solubility experiments (corresponding to the results in Fig. 3). ${ }^{20}$
Tables A3 and A4 shows analyses of electrolyte solutions in the kinetic dissolution experiments (corresponding to the results in Fig. 4 after $200 \mathrm{~d}$ of dissolution).

Table A5 shows analyses of $0.5 \mathrm{M}\left(\mathrm{NH}_{4}\right)_{2} \mathrm{CO}_{3}$ electrolyte after $19 \mathrm{~d}$ of extraction following $197 \mathrm{~d}$ of equilibration in $\mathrm{Na}-\mathrm{Ca}-\mathrm{NO})_{3}-\mathrm{HCO}_{3}$ electrolyte ( $\mathrm{pH}$ 7.02) (corresponding to the results in Fig. 5).

Table A1. Selected solutes in $\mathrm{Na}-\mathrm{NO}_{3}-\mathrm{HCO}_{3}$ electrolyte after 197 days of equilibration.

\begin{tabular}{|c|c|c|c|c|c|c|c|c|c|c|}
\hline Sediment & $\mathrm{pH}^{\mathrm{a}}$ & $\mathrm{pH}^{\mathrm{b}}$ & $\begin{array}{c}\mathrm{UO}_{2}{ }^{2+} \\
(\mu \mathrm{mol} / \mathrm{L})\end{array}$ & $\begin{array}{c}\mathrm{H}_{4} \mathrm{SiO}_{4} \\
(\mu \mathrm{mol} / \mathrm{L}) \\
\end{array}$ & $\begin{array}{c}\mathrm{PO}_{4}{ }^{3-} \\
(\mu \mathrm{mol} / \mathrm{L}) \\
\end{array}$ & $\begin{array}{c}\mathrm{Na}^{+} \\
(\mathrm{mmol} / \mathrm{L}) \\
\end{array}$ & $\begin{array}{c}\mathrm{Ca}^{2+} \\
(\mu \mathrm{mol} / \mathrm{L})\end{array}$ & $\begin{array}{c}\mathrm{Mg}^{2+} \\
(\mu \mathrm{mol} / \mathrm{L}) \\
\end{array}$ & $\begin{array}{c}\mathrm{C}_{\text {inorganic }} \\
(\mathrm{mmol} / \mathrm{L})\end{array}$ & $\mathrm{I}^{\mathrm{c}}$ \\
\hline BX-102 & 6.95 & 8.06 & 10.56 & 271.7 & bd & 49.87 & 864.6 & 336.6 & 1.620 & 0.05 \\
\hline \multirow[t]{11}{*}{ I53 } & 6.95 & 8.01 & 11.35 & 299.4 & bd & 49.33 & 880.5 & 374.9 & 1.631 & 0.05 \\
\hline & 7.27 & 7.98 & 10.52 & 272.6 & bd & 44.50 & 825.3 & 318.4 & 1.616 & 0.05 \\
\hline & 7.27 & 7.95 & 13.06 & 283.5 & bd & 46.45 & 829.8 & 343.2 & 1.598 & 0.05 \\
\hline & 7.61 & 8.03 & 14.63 & 301.0 & bd & 51.20 & 752.0 & 360.4 & 1.737 & 0.05 \\
\hline & 7.61 & 8.04 & 14.18 & 273.4 & bd & 51.85 & 730.8 & 307.7 & 1.858 & 0.05 \\
\hline & 8.16 & 8.14 & 17.08 & 269.5 & bd & 47.61 & 513.5 & 220.8 & 2.166 & 0.05 \\
\hline & 8.16 & 8.17 & 18.00 & 289.3 & bd & 50.28 & 522.5 & 297.5 & 2.153 & 0.05 \\
\hline & 8.67 & 8.55 & 46.65 & 273.5 & bd & 47.63 & 213.6 & 161.9 & 5.234 & 0.05 \\
\hline & 8.67 & 8.53 & 46.50 & 279.5 & bd & 49.28 & 262.5 & 212.9 & 4.661 & 0.05 \\
\hline & 9.25 & 9.16 & 83.50 & 339.9 & bd & 46.89 & 56.10 & 115.9 & 20.16 & 0.05 \\
\hline & 9.25 & 9.14 & 68.90 & 345.7 & bd & 43.93 & 49.60 & 118.2 & 19.63 & 0.05 \\
\hline BX-102 & 6.95 & 8.31 & 33.24 & 267.2 & 55.56 & 48.67 & 297.2 & 91.13 & 2.733 & 0.05 \\
\hline \multirow[t]{11}{*}{ I61 } & 6.95 & 8.29 & 32.06 & 253.7 & 60.26 & 47.54 & 324.0 & 87.62 & 2.612 & 0.05 \\
\hline & 7.27 & 8.28 & 32.80 & 277.0 & 57.85 & 55.02 & 302.6 & 98.98 & 2.810 & 0.05 \\
\hline & 7.27 & 8.34 & 34.06 & 320.6 & 67.14 & 55.24 & 283.6 & 98.11 & 2.854 & 0.05 \\
\hline & 7.61 & 8.35 & 37.56 & 240.7 & 55.50 & 52.07 & 264.5 & 75.20 & 2.957 & 0.05 \\
\hline & 7.61 & 8.37 & 36.93 & 218.8 & 56.95 & 51.94 & 255.1 & 71.33 & 3.100 & 0.05 \\
\hline & 8.16 & 8.44 & 42.43 & 206.7 & 63.38 & 51.81 & 200.0 & 66.86 & 3.766 & 0.05 \\
\hline & 8.16 & 8.43 & 44.47 & 236.6 & 59.08 & 51.72 & 193.6 & 73.76 & 3.836 & 0.05 \\
\hline & 8.67 & 8.71 & 54.06 & 219.9 & 73.98 & 51.63 & 79.49 & 44.78 & 7.275 & 0.05 \\
\hline & 8.67 & 8.73 & 59.49 & 241.7 & 83.14 & 50.89 & 81.80 & 50.67 & 7.671 & 0.05 \\
\hline & 9.25 & 9.21 & 179.1 & 299.8 & 87.41 & 50.33 & 55.03 & 40.55 & 22.31 & 0.05 \\
\hline & 9.25 & 9.21 & 189.4 & 288.4 & 96.89 & 50.59 & 59.34 & 36.18 & 22.42 & 0.05 \\
\hline BX-102 & 6.95 & 8.13 & 17.74 & 238.5 & bd & 47.64 & 798.5 & 177.2 & 1.663 & 0.05 \\
\hline \multirow[t]{11}{*}{ I67 } & 6.95 & 8.13 & 18.09 & 207.6 & bd & 49.89 & 811.6 & 168.7 & 1.699 & 0.05 \\
\hline & 7.27 & 8.11 & 19.49 & 211.3 & bd & 49.80 & 784.2 & 173.7 & 1.716 & 0.05 \\
\hline & 7.27 & 8.06 & 20.15 & 237.0 & bd & 49.46 & 791.0 & 186.6 & 1.689 & 0.05 \\
\hline & 7.61 & 8.01 & 20.87 & 222.8 & bd & 49.85 & 699.2 & 172.8 & 1.798 & 0.05 \\
\hline & 7.61 & 8.06 & 22.78 & 214.3 & bd & 49.72 & 711.1 & 157.8 & 1.826 & 0.05 \\
\hline & 8.16 & 8.19 & 26.30 & 206.7 & bd & 50.15 & 493.5 & 125.8 & 2.299 & 0.05 \\
\hline & 8.16 & 8.21 & 25.76 & 228.1 & bd & 51.33 & 514.2 & 148.5 & 2.319 & 0.05 \\
\hline & 8.67 & 8.53 & 74.82 & 233.6 & bd & 46.98 & 218.3 & 83.47 & 5.036 & 0.05 \\
\hline & 8.67 & 8.53 & 66.23 & 222.7 & bd & 48.15 & 195.2 & 61.97 & 5.084 & 0.05 \\
\hline & 9.25 & 9.11 & 219.7 & 331.5 & bd & 47.24 & 64.51 & 49.67 & 20.00 & 0.05 \\
\hline & 9.25 & 9.04 & 220.9 & 325.0 & bd & 46.85 & 71.95 & 51.64 & 19.86 & 0.05 \\
\hline
\end{tabular}

${ }^{\text {a }}$ Electrolyte $\mathrm{pH}$ was the solution $\mathrm{pH}$ before contacting sediments (see Table 4).

${ }^{\mathrm{b}}$ Suspension $\mathrm{pH}$ was the $\mathrm{pH}$ measured in the suspensions after 197 days of equilibration.

${ }^{\mathrm{c}}$ Ionic strength in the suspensions after 197 days of equilibration. All solutes are total concentrations; bd: below detection limit. 
Table A2. Selected solutes in Na-Ca- $\mathrm{ClO}_{4}-\mathrm{HCO}_{3}$ electrolyte after 197 days of equilibration.

\begin{tabular}{|c|c|c|c|c|c|c|c|c|c|c|}
\hline Sediment & $\mathrm{pH}^{\mathrm{a}}$ & $\mathrm{pH}^{\mathrm{b}}$ & $\begin{array}{c}\mathrm{UO}_{2}^{2+} \\
(\mu \mathrm{mol} / \mathrm{L})\end{array}$ & $\begin{array}{c}\mathrm{H}_{4} \mathrm{SiO}_{4} \\
(\mu \mathrm{mol} / \mathrm{L})\end{array}$ & $\begin{array}{c}\mathrm{PO}_{4}{ }^{3-} \\
(\mu \mathrm{mol} / \mathrm{L})\end{array}$ & $\begin{array}{c}\mathrm{Na}^{+} \\
(\mathrm{mmol} / \mathrm{L})\end{array}$ & $\begin{array}{c}\mathrm{Ca}^{2+} \\
(\mu \mathrm{mol} / \mathrm{L})\end{array}$ & $\begin{array}{c}\mathrm{Mg}^{2+} \\
(\mu \mathrm{mol} / \mathrm{L})\end{array}$ & $\begin{array}{c}\mathrm{C}_{\text {inorganic }} \\
(\mathrm{mmol} / \mathrm{L})\end{array}$ & $\mathrm{I}^{\mathrm{c}}$ \\
\hline BX-102 & 7.59 & 7.44 & 12.46 & 283.4 & bd & 61.81 & 19.99 & 0.760 & 0.455 & 0.10 \\
\hline \multirow[t]{9}{*}{ I53 } & 7.59 & 7.24 & 11.76 & 256.5 & bd & 60.94 & 19.63 & 0.661 & 0.459 & 0.10 \\
\hline & 8.05 & 7.92 & 12.12 & 258.1 & bd & 89.21 & 2.003 & 0.449 & 1.215 & 0.09 \\
\hline & 8.05 & 7.93 & 11.14 & 244.8 & bd & 87.08 & 2.001 & 0.443 & 1.240 & 0.09 \\
\hline & 8.35 & 8.20 & 24.81 & 246.8 & bd & 88.30 & 0.833 & 0.349 & 2.271 & 0.09 \\
\hline & 8.35 & 8.19 & 25.48 & 252.1 & bd & 87.34 & 0.873 & 0.378 & 2.250 & 0.09 \\
\hline & 8.37 & 8.11 & 20.57 & 294.5 & bd & 46.50 & 0.626 & 0.240 & 2.173 & 0.05 \\
\hline & 8.37 & 8.11 & 18.67 & 253.9 & bd & 46.28 & 0.588 & 0.208 & 2.217 & 0.05 \\
\hline & 8.96 & 8.69 & 55.79 & 261.0 & bd & 49.93 & 0.136 & 0.139 & 7.324 & 0.05 \\
\hline & 8.96 & 8.61 & 55.82 & 295.3 & bd & 48.35 & 0.137 & 0.153 & 7.591 & 0.05 \\
\hline BX-102 & 7.59 & 7.68 & 43.53 & 302.1 & bd & 65.03 & 18.23 & 0.385 & 0.760 & 0.10 \\
\hline \multirow[t]{9}{*}{ I61 } & 7.59 & 7.72 & 40.14 & 293.9 & bd & 67.94 & 16.61 & 0.364 & 0.763 & 0.10 \\
\hline & 8.05 & 8.12 & 34.74 & 243.9 & 44.94 & 88.34 & 1.025 & 0.155 & 1.729 & 0.09 \\
\hline & 8.05 & 8.14 & 38.13 & 265.3 & 41.49 & 87.34 & 0.966 & 0.171 & 1.751 & 0.09 \\
\hline & 8.35 & 8.42 & 47.21 & 227.9 & 54.77 & 90.87 & 0.299 & 0.112 & 3.396 & 0.09 \\
\hline & 8.35 & 8.41 & 41.93 & 209.6 & 58.03 & 92.52 & 0.306 & 0.106 & 3.486 & 0.09 \\
\hline & 8.37 & 8.21 & 46.11 & 246.6 & 64.22 & 49.67 & 0.190 & 0.071 & 3.726 & 0.05 \\
\hline & 8.37 & 8.22 & 43.79 & 276.1 & 57.65 & 49.67 & 0.183 & 0.071 & 3.551 & 0.05 \\
\hline & 8.96 & 8.71 & 67.65 & 259.2 & 72.64 & 52.07 & 0.060 & 0.044 & 10.59 & 0.05 \\
\hline & 8.96 & 8.72 & 68.36 & 240.3 & 65.83 & 52.41 & 0.060 & 0.044 & 10.61 & 0.05 \\
\hline BX-102 & 7.59 & 7.44 & 19.63 & 237.0 & bd & 64.85 & 19.59 & 0.458 & 0.482 & 0.10 \\
\hline \multirow[t]{9}{*}{ I67 } & 7.59 & 7.46 & 19.35 & 251.4 & bd & 61.24 & 19.33 & 0.512 & 0.475 & 0.10 \\
\hline & 8.05 & 7.90 & 18.11 & 226.6 & bd & 84.69 & 1.838 & 0.250 & 1.320 & 0.09 \\
\hline & 8.05 & 7.88 & 21.29 & 241.9 & bd & 85.99 & 1.964 & 0.234 & 1.353 & 0.09 \\
\hline & 8.35 & 8.18 & 42.44 & 215.9 & bd & 85.52 & 0.807 & 0.190 & 2.185 & 0.09 \\
\hline & 8.35 & 8.14 & 43.19 & 265.1 & bd & 86.78 & 0.879 & 0.238 & 2.104 & 0.09 \\
\hline & 8.37 & 8.11 & 37.43 & 231.3 & bd & 47.32 & 0.560 & 0.130 & 2.204 & 0.05 \\
\hline & 8.37 & 8.15 & 37.20 & 223.8 & bd & 47.24 & 0.590 & 0.128 & 2.213 & 0.05 \\
\hline & 8.96 & 8.65 & 141.8 & 265.9 & bd & 49.59 & 0.161 & 0.086 & 7.639 & 0.05 \\
\hline & 8.96 & 8.52 & 124.2 & 231.5 & bd & 50.28 & 0.155 & 0.068 & 7.566 & 0.05 \\
\hline
\end{tabular}

${ }^{\mathrm{a}}$ Electrolyte $\mathrm{pH}$ was the solution $\mathrm{pH}$ before contacting sediments (see Table 4).

${ }^{\mathrm{b}}$ Suspension $\mathrm{pH}$ was the $\mathrm{pH}$ measured in the suspensions after 197 days of equilibration.

${ }^{\mathrm{c}}$ Ionic strength in the suspensions after 197 days of equilibration. All solutes are total concentrations; bd: below detection limit.

Table A3. Selected solutes in $\mathrm{Na}-\mathrm{NO}_{3}-\mathrm{HCO}_{3}$ electrolyte after 200 days of equilibration.

\begin{tabular}{|c|c|c|c|c|c|c|c|c|c|c|}
\hline Sediment & $\mathrm{pH}^{\mathrm{a}}$ & $\mathrm{pH}^{\mathrm{b}}$ & $\begin{array}{c}\mathrm{UO}_{2}{ }^{2+} \\
(\mu \mathrm{mol} / \mathrm{L})\end{array}$ & $\begin{array}{c}\mathrm{H}_{4} \mathrm{SiO}_{4} \\
(\mu \mathrm{mol} / \mathrm{L})\end{array}$ & $\begin{array}{c}\mathrm{PO}_{4}{ }^{3-} \\
(\mu \mathrm{mol} / \mathrm{L})\end{array}$ & $\begin{array}{c}\mathrm{Na}^{+} \\
(\mathrm{mmol} / \mathrm{L})\end{array}$ & $\begin{array}{c}\mathrm{Ca}^{2+} \\
(\mu \mathrm{mol} / \mathrm{L})\end{array}$ & $\begin{array}{c}\mathrm{Mg}^{2+} \\
(\mu \mathrm{mol} / \mathrm{L})\end{array}$ & $\begin{array}{c}\mathrm{C}_{\text {inorganic }} \\
(\mathrm{mmol} / \mathrm{L})\end{array}$ & $\mathrm{I}^{\mathrm{c}}$ \\
\hline BX-102 & 7.27 & 8.13 & 10.52 & 261.8 & bd & 48.95 & 760.0 & 304.1 & 1.608 & 0.05 \\
\hline \multirow[t]{3}{*}{ I53 } & 7.27 & 8.07 & 9.524 & 253.2 & bd & 51.33 & 768.9 & 314.1 & 1.578 & 0.05 \\
\hline & 9.25 & 9.07 & 83.62 & 295.2 & 7.026 & 46.32 & 54.80 & 104.2 & 20.96 & 0.05 \\
\hline & 9.25 & 9.06 & 91.16 & 298.3 & 7.788 & 43.93 & 58.00 & 109.5 & 20.18 & 0.05 \\
\hline BX-102 & 7.27 & 8.31 & 26.98 & 255.2 & 51.91 & 47.24 & 200.0 & 69.60 & 2.348 & 0.05 \\
\hline \multirow[t]{3}{*}{ I61 } & 7.27 & 8.29 & 28.53 & 257.8 & 59.70 & 52.41 & 193.4 & 68.80 & 2.236 & 0.05 \\
\hline & 9.25 & 9.19 & 210.7 & 333.1 & 102.9 & 49.76 & 58.70 & 42.40 & 22.79 & 0.05 \\
\hline & 9.25 & 9.20 & 176.9 & 316.2 & 97.18 & 47.59 & 53.10 & 42.20 & 22.66 & 0.05 \\
\hline BX-102 & 7.27 & 8.08 & 15.32 & 236.4 & bd & 43.93 & 672.7 & 184.5 & 1.424 & 0.05 \\
\hline \multirow[t]{3}{*}{ I67 } & 7.27 & 8.08 & 15.70 & 233.5 & bd & 49.20 & 691.4 & 175.2 & 1.503 & 0.05 \\
\hline & 9.25 & 9.09 & 250.7 & 315.1 & bd & 47.72 & 64.50 & 52.60 & 20.46 & 0.05 \\
\hline & 9.25 & 9.08 & 248.2 & 323.8 & bd & 47.24 & 64.40 & 51.80 & 20.34 & 0.05 \\
\hline
\end{tabular}

${ }^{\mathrm{a}}$ Electrolyte $\mathrm{pH}$ was the solution $\mathrm{pH}$ before contacting sediments (see Table 4).

${ }^{\mathrm{b}}$ Suspension $\mathrm{pH}$ was the $\mathrm{pH}$ measured in the suspensions after 200 days of equilibration.

${ }^{\mathrm{c}}$ Ionic strength in the suspensions after 200 days of equilibration. All solutes are total concentrations; bd: below detection limit. 
Table A4. Selected solutes in $\mathrm{Na}-\mathrm{Ca}-\mathrm{ClO}_{4}-\mathrm{HCO}_{3}$ electrolyte after 197 days of equilibration.

\begin{tabular}{|c|c|c|c|c|c|c|c|c|c|c|}
\hline Sediment & $\mathrm{pH}^{\mathrm{a}}$ & $\mathrm{pH}^{\mathrm{b}}$ & $\begin{array}{c}\mathrm{UO}_{2}^{2+} \\
(\mu \mathrm{mol} / \mathrm{L})\end{array}$ & $\begin{array}{c}\mathrm{H}_{4} \mathrm{SiO}_{4} \\
(\mu \mathrm{mol} / \mathrm{L})\end{array}$ & $\begin{array}{c}\mathrm{PO}_{4}{ }^{3-} \\
(\mu \mathrm{mol} / \mathrm{L})\end{array}$ & $\begin{array}{c}\mathrm{Na}^{+} \\
(\mathrm{mmol} / \mathrm{L})\end{array}$ & $\begin{array}{c}\mathrm{Ca}^{2+} \\
(\mu \mathrm{mol} / \mathrm{L})\end{array}$ & $\begin{array}{c}\mathrm{Mg}^{2+} \\
(\mu \mathrm{mol} / \mathrm{L})\end{array}$ & $\begin{array}{l}\mathrm{C}_{\text {inorganic }} \\
(\mathrm{mmol} / \mathrm{L})\end{array}$ & $\mathrm{I}^{\mathrm{c}}$ \\
\hline BX-102 & 7.59 & 7.71 & 11.29 & 282.7 & bd & 56.67 & 18.28 & 0.790 & 0.503 & 0.10 \\
\hline \multirow[t]{3}{*}{ I53 } & 7.59 & 7.60 & 10.25 & 294.7 & bd & 53.81 & 18.72 & 0.789 & 0.453 & 0.10 \\
\hline & 8.96 & 8.70 & 59.70 & 306.8 & bd & 45.76 & 0.153 & 0.170 & 7.406 & 0.05 \\
\hline & 8.96 & 8.67 & 72.20 & 300.3 & bd & 48.80 & 0.173 & 0.164 & 7.613 & 0.05 \\
\hline
\end{tabular}

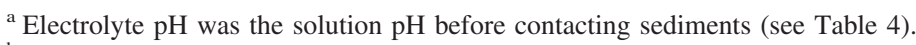

${ }^{\mathrm{b}}$ Suspension $\mathrm{pH}$ was the $\mathrm{pH}$ measured in the suspensions after 197 days of equilibration.

${ }^{\mathrm{c}}$ Ionic strength in the suspensions after 197 days of equilibration. All solutes are total concentrations; bd: below detection limit.

Table A5. Selected solutes in $\left(\mathrm{NH}_{4}\right)_{2} \mathrm{CO}_{3}$ electrolyte after 19 days of extraction.

\begin{tabular}{lcccccccc}
\hline Sediment & $\mathrm{pH}^{\mathrm{a}}$ & $\mathrm{pH}^{\mathrm{b}}$ & $\begin{array}{c}\mathrm{UO}_{2}{ }^{2+} \\
(\mu \mathrm{mol} / \mathrm{L})\end{array}$ & $\begin{array}{c}\mathrm{H}_{4} \mathrm{SiO}_{4} \\
(\mu \mathrm{mol} / \mathrm{L})\end{array}$ & $\begin{array}{c}\mathrm{PO}_{4}{ }^{3-} \\
(\mu \mathrm{mol} / \mathrm{L})\end{array}$ & $\begin{array}{c}\mathrm{Na}^{+} \\
(\mathrm{mmol} / \mathrm{L})\end{array}$ & $\begin{array}{c}\mathrm{Ca}^{2+} \\
(\mu \mathrm{mol} / \mathrm{L})\end{array}$ & $\begin{array}{c}\mathrm{Mg}^{2+} \\
(\mu \mathrm{mol} / \mathrm{L})\end{array}$ \\
\hline BX-102 & 8.43 & 8.95 & 84.27 & 156.8 & 15.01 & 0.311 & 88.09 & 49.31 \\
I53 & 8.43 & 8.89 & 98.33 & 179.4 & 27.38 & 0.245 & 79.57 & 59.54 \\
BX-102 & 8.43 & 8.92 & 215.8 & 187.6 & 102.5 & 0.371 & 83.19 & 44.93 \\
I61 & 8.43 & 8.96 & 211.5 & 182.7 & 104.8 & 0.385 & 79.43 & 43.78 \\
BX-102 & 8.43 & 8.85 & 230.8 & 215.8 & 20.05 & 0.290 & 85.31 & 44.33 \\
I67 & 8.43 & 8.80 & 243.3 & 204.8 & 13.24 & 0.525 & 102.3 & 44.35 \\
\hline
\end{tabular}

${ }^{a}$ Electrolyte $\mathrm{pH}$ was the solution $\mathrm{pH}$ before contacting sediments.

${ }^{\mathrm{b}}$ Suspension $\mathrm{pH}$ was the $\mathrm{pH}$ measured in the suspensions after 19 days of equilibration. All solutes are total concentrations. 
APPENDIX B

\section{Calculated Uranyl Solubility in Uranium Dissolution}

\section{Experiments}

The calculated solubilities of Na-boltwoodite and uranophane were plotted in Figure 3, because they matched best with the experimental results.

Table B1. Calculated solubility ( $\mu \mathrm{mol} / \mathrm{L} \mathrm{U})$ of uranyl minerals in the sediment suspensions with Na-electrolyte. ${ }^{\text {a }}$

\begin{tabular}{|c|c|c|c|c|c|c|c|c|c|}
\hline Sediment & $\begin{array}{c}\text { Suspension } \\
\text { pH }\end{array}$ & $\begin{array}{c}\mathrm{Na}- \\
\text { boltwoodite }\end{array}$ & Soddyite & Uranophane & $\begin{array}{c}\mathrm{Na}- \\
\text { Weeksite }\end{array}$ & Clarkeite & Becquerelite & Zellerite & $\begin{array}{c}\mathrm{Na}- \\
\text { autunite }\end{array}$ \\
\hline BX-102 & 8.06 & 5.735 & 94.12 & 11.93 & 94.12 & 94.12 & 48.56 & 94.12 & 56.95 \\
\hline \multirow[t]{11}{*}{ I53 } & 8.01 & 5.245 & 87.29 & 10.78 & 94.12 & 94.12 & 47.86 & 94.12 & 54.05 \\
\hline & 7.98 & 5.747 & 82.67 & 10.99 & 94.12 & 94.12 & 44.58 & 94.12 & 51.42 \\
\hline & 7.95 & 5.133 & 76.75 & 10.25 & 94.12 & 94.12 & 42.58 & 94.12 & 49.31 \\
\hline & 8.03 & 5.543 & 94.12 & 12.68 & 94.12 & 94.12 & 53.48 & 94.12 & 58.40 \\
\hline & 8.04 & 7.153 & 94.12 & 16.53 & 94.12 & 94.12 & 62.57 & 94.12 & 62.73 \\
\hline & 8.14 & 10.90 & 94.12 & 26.47 & 94.12 & 94.12 & 88.72 & 94.12 & 85.03 \\
\hline & 8.17 & 9.996 & 94.12 & 25.52 & 94.12 & 94.12 & 90.26 & 94.12 & 88.33 \\
\hline & 8.55 & 94.12 & 94.12 & 94.12 & 94.12 & 94.12 & 94.12 & 94.12 & 94.12 \\
\hline & 8.53 & 94.12 & 94.12 & 94.12 & 94.12 & 94.12 & 94.12 & 94.12 & 94.12 \\
\hline & 9.16 & 94.12 & 94.12 & 94.12 & 94.12 & 94.12 & 94.12 & 94.12 & 94.12 \\
\hline & 9.14 & 94.12 & 94.12 & 94.12 & 94.12 & 94.12 & 94.12 & 94.12 & 94.12 \\
\hline BX-102 & 8.31 & 21.85 & 339.5 & 61.40 & 233.2 & 267.1 & 165.6 & 339.5 & 121.9 \\
\hline \multirow[t]{11}{*}{ I61 } & 8.29 & 20.46 & 339.5 & 55.02 & 223.7 & 252.0 & 146.9 & 339.5 & 109.2 \\
\hline & 8.28 & 20.53 & 339.5 & 63.70 & 225.4 & 270.7 & 175.5 & 339.5 & 116.4 \\
\hline & 8.34 & 19.82 & 339.5 & 64.46 & 232.6 & 274.4 & 187.1 & 339.5 & 128.6 \\
\hline & 8.35 & 29.45 & 339.5 & 83.82 & 263.9 & 293.7 & 203.4 & 339.5 & 144.8 \\
\hline & 8.37 & 36.34 & 339.5 & 98.48 & 284.6 & 318.1 & 227.5 & 339.5 & 159.3 \\
\hline & 8.44 & 63.72 & 339.5 & 159.1 & 339.5 & 339.5 & 339.5 & 339.5 & 234.2 \\
\hline & 8.43 & 60.48 & 339.5 & 157.1 & 339.5 & 339.5 & 339.5 & 339.5 & 238.8 \\
\hline & 8.71 & 284.8 & 339.5 & 339.5 & 339.5 & 339.5 & 339.5 & 339.5 & 339.5 \\
\hline & 8.73 & 313.2 & 339.5 & 339.5 & 339.5 & 339.5 & 339.5 & 339.5 & 339.5 \\
\hline & 9.21 & 339.5 & 339.5 & 339.5 & 339.5 & 339.5 & 339.5 & 339.5 & 339.5 \\
\hline & 9.21 & 339.5 & 339.5 & 339.5 & 339.5 & 339.5 & 339.5 & 339.5 & 339.5 \\
\hline BX-102 & 8.13 & 9.023 & 260.7 & 21.28 & 150.1 & 160.8 & 62.09 & 274.8 & 75.74 \\
\hline \multirow[t]{12}{*}{ I67 } & 8.13 & 10.56 & 274.8 & 25.14 & 157.8 & 161.9 & 65.52 & 274.8 & 76.78 \\
\hline & 8.11 & 10.49 & 274.8 & 25.35 & 156.7 & 167.8 & 66.06 & 274.8 & 75.87 \\
\hline & 8.06 & 8.723 & 251.4 & 21.43 & 144.8 & 173.2 & 61.38 & 274.8 & 69.91 \\
\hline & 8.01 & 10.28 & 274.8 & 26.33 & 150.3 & 201.6 & 68.61 & 274.8 & 69.14 \\
\hline & 8.06 & 11.69 & 274.8 & 29.12 & 160.1 & 195.7 & 75.58 & 274.8 & 76.69 \\
\hline & 8.19 & 23.65 & 274.8 & 60.80 & 214.0 & 256.4 & 137.0 & 274.8 & 120.0 \\
\hline & 8.21 & 22.00 & 274.8 & 62.29 & 212.4 & 253.2 & 143.2 & 274.8 & 123.8 \\
\hline & 8.53 & 183.7 & 274.8 & 274.8 & 274.8 & 274.8 & 274.8 & 274.8 & 274.8 \\
\hline & 8.53 & 185.4 & 274.8 & 274.8 & 274.8 & 274.8 & 274.8 & 274.8 & 274.8 \\
\hline & 9.11 & 274.8 & 274.8 & 274.8 & 274.8 & 274.8 & 274.8 & 274.8 & 274.8 \\
\hline & 9.04 & 274.8 & 274.8 & 274.8 & 274.8 & 274.8 & 274.8 & 274.8 & 274.8 \\
\hline & 9.06 & 274.8 & 274.8 & 274.8 & 274.8 & 274.8 & 274.8 & 274.8 & 274.8 \\
\hline
\end{tabular}

${ }^{\text {a }}$ Calculated solubilities were limited by the total amount of $\mathrm{U}$ in the sediments. All of the $\mathrm{U}$ often dissolved at high pH. 
Table B2. Calculated solubility ( $\mu \mathrm{mol} / \mathrm{L} \mathrm{U}$ ) of uranyl minerals in the sediment suspensions with $\mathrm{Na}-\mathrm{Ca}-\mathrm{electrolyte}{ }^{\text {a }}$

\begin{tabular}{|c|c|c|c|c|c|c|c|c|c|}
\hline Sediment & $\begin{array}{c}\text { Suspension } \\
\mathrm{pH}\end{array}$ & $\begin{array}{c}\mathrm{Na}- \\
\text { boltwoodite }\end{array}$ & Soddyite & Uranophane & $\begin{array}{c}\text { Na- } \\
\text { Weeksite }\end{array}$ & Clarkeite & Becquerelite & Zellerite & $\begin{array}{c}\mathrm{Na}- \\
\text { autunite }\end{array}$ \\
\hline BX-102 & 7.44 & 5.378 & 61.52 & 3.315 & 94.12 & 94.12 & 20.10 & 94.12 & 30.49 \\
\hline \multirow[t]{9}{*}{ I53 } & 7.24 & 5.286 & 53.16 & 3.225 & 94.12 & 94.12 & 15.90 & 94.12 & 23.31 \\
\hline & 7.92 & 3.056 & 94.12 & 7.678 & 82.58 & 87.08 & 34.92 & 94.12 & 39.66 \\
\hline & 7.93 & 3.512 & 94.12 & 8.565 & 87.76 & 91.42 & 37.03 & 94.12 & 39.66 \\
\hline & 8.20 & 11.57 & 94.12 & 38.22 & 94.12 & 94.12 & 94.12 & 94.12 & 94.12 \\
\hline & 8.19 & 11.33 & 94.12 & 36.56 & 94.12 & 94.12 & 94.12 & 94.12 & 86.96 \\
\hline & 8.11 & 11.03 & 94.12 & 24.16 & 94.12 & 94.12 & 89.95 & 94.12 & 86.96 \\
\hline & 8.11 & 12.96 & 94.12 & 28.51 & 94.12 & 94.12 & 93.03 & 94.12 & 86.95 \\
\hline & 8.69 & 94.12 & 94.12 & 94.12 & 94.12 & 94.12 & 94.12 & 94.12 & 94.12 \\
\hline & 8.61 & 94.12 & 94.12 & 94.12 & 94.12 & 94.12 & 94.12 & 94.12 & 94.12 \\
\hline BX-102 & 7.68 & 20.81 & 145.3 & 14.85 & 117.5 & 165.7 & 69.28 & 339.5 & 83.02 \\
\hline \multirow[t]{9}{*}{ I61 } & 7.72 & 18.84 & 146.0 & 14.34 & 115.1 & 155.7 & 67.44 & 339.5 & 80.68 \\
\hline & 8.12 & 6.066 & 270.8 & 19.58 & 131.2 & 109.5 & 65.11 & 339.5 & 49.79 \\
\hline & 8.14 & 5.762 & 276.6 & 19.06 & 131.2 & 109.5 & 66.70 & 339.5 & 54.80 \\
\hline & 8.42 & 37.31 & 339.5 & 134.9 & 302.7 & 310.7 & 309.8 & 339.5 & 185.1 \\
\hline & 8.41 & 40.99 & 339.5 & 143.4 & 307.9 & 326.2 & 325.2 & 339.5 & 185.1 \\
\hline & 8.21 & 45.54 & 339.5 & 126.1 & 294.2 & 339.5 & 302.4 & 339.5 & 156.0 \\
\hline & 8.22 & 63.97 & 339.5 & 110.6 & 276.0 & 339.5 & 276.4 & 339.5 & 149.6 \\
\hline & 8.71 & 339.5 & 339.5 & 339.5 & 339.5 & 339.5 & 339.5 & 339.5 & 339.5 \\
\hline & 8.72 & 339.5 & 339.5 & 339.5 & 339.5 & 339.5 & 339.5 & 339.5 & 339.5 \\
\hline BX-102 & 7.44 & 4.508 & 61.37 & 3.235 & 74.19 & 133.6 & 16.04 & 274.8 & 31.03 \\
\hline \multirow[t]{9}{*}{ I67 } & 7.46 & 4.302 & 59.64 & 2.939 & 71.85 & 133.4 & 15.72 & 274.8 & 31.46 \\
\hline & 7.90 & 3.600 & 173.8 & 10.33 & 96.86 & 99.77 & 35.68 & 274.8 & 41.78 \\
\hline & 7.88 & 3.701 & 174.6 & 10.43 & 96.44 & 107.3 & 38.07 & 274.8 & 43.97 \\
\hline & 8.18 & 15.54 & 274.8 & 52.59 & 188.7 & 183.5 & 126.8 & 274.8 & 108.7 \\
\hline & 8.14 & 11.04 & 274.8 & 39.87 & 166.9 & 173.6 & 113.8 & 274.8 & 100.0 \\
\hline & 8.11 & 19.74 & 274.8 & 48.67 & 198.9 & 261.8 & 116.8 & 274.8 & 109.9 \\
\hline & 8.15 & 21.41 & 274.8 & 50.85 & 207.0 & 256.2 & 120.9 & 274.8 & 116.8 \\
\hline & 8.65 & 274.8 & 274.8 & 274.8 & 274.8 & 274.8 & 274.8 & 274.8 & 274.8 \\
\hline & 8.52 & 274.8 & 274.8 & 274.8 & 274.8 & 274.8 & 274.8 & 274.8 & 274.8 \\
\hline
\end{tabular}

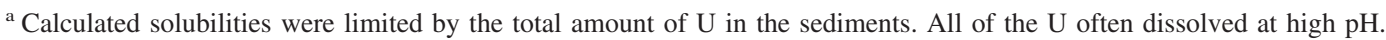

